NBER WORKING PAPER SERIES

\title{
EXPERIMENTAL EVIDENCE ON THE DEMAND FOR AND COSTS OF RURAL ELECTRIFICATION
}

\author{
Kenneth Lee \\ Edward Miguel \\ Catherine Wolfram \\ Working Paper 22292 \\ http://www.nber.org/papers/w22292
NATIONAL BUREAU OF ECONOMIC RESEARCH
1050 Massachusetts Avenue
Cambridge, MA 02138
May 2016

This research was supported by the Development Impact Lab (USAID Cooperative Agreements AID-OAA-A-13-00002 and AIDOAA-A-12-00011, part of the USAID Higher Education Solutions Network), the Berkeley Energy and Climate Institute, the Blum Center for Developing Economies, the U.C. Center for Energy and Environmental Economics, the Center for Effective Global Action, the Weiss Family Program Fund for Research in Development Economics, the World Bank, and an anonymous donor. We thank Francis Meyo, Victor Bwire, Susanna Berkouwer, Elisa Cascardi, Corinne Cooper, Eric Hsu, Radhika Kannan, Anna Kasimatis, and Tomas Monárrez for excellent research assistance, as well as colleagues at Innovations for Poverty Action Kenya. This research would not have been possible without the support and cooperation of partners at the Rural Electrification Authority and Kenya Power. Hunt Allcott, David Atkin, Raj Chetty, Carson Christiano, Maureen Cropper, Aluma Dembo, Esther Duflo, Kelsey Jack, Marc Jeuland, Asim Khwaja, Mushfiq Mobarak, Samson Ondiek, Billy Pizer, Matthew Podolsky, Javier Rosa, Mark Rosenzweig, Manisha Shah, Jay Taneja, Duncan Thomas, Chris Timmins, Liam Wren-Lewis, and many seminar participants have provided helpful comments. All errors remain our own. The views expressed herein are those of the authors and do not necessarily reflect the views of the National Bureau of Economic Research.

NBER working papers are circulated for discussion and comment purposes. They have not been peer-reviewed or been subject to the review by the NBER Board of Directors that accompanies official NBER publications.

(C) 2016 by Kenneth Lee, Edward Miguel, and Catherine Wolfram. All rights reserved. Short sections of text, not to exceed two paragraphs, may be quoted without explicit permission provided that full credit, including $(\odot$ notice, is given to the source. 
Experimental Evidence on the Demand for and Costs of Rural Electrification

Kenneth Lee, Edward Miguel, and Catherine Wolfram

NBER Working Paper No. 22292

May 2016

JEL No. L12,L94,O13,Q41

\begin{abstract}
$\underline{\text { ABSTRACT }}$
We present results from an experiment that randomized the expansion of electric grid infrastructure in rural Kenya. Electricity distribution is the canonical example of a natural monopoly. Randomized price offers show that demand for electricity connections falls sharply with price. Experimental variation in the number of connections combined with administrative cost data reveals considerable scale economies, as hypothesized. However, consumer surplus is far less than total costs at all price levels, suggesting that residential electrification may reduce social welfare. We discuss how leakage, reduced demand (due to red tape, low reliability, and credit constraints), and spillovers may impact this conclusion.
\end{abstract}

Kenneth Lee

Department of Agricultural and Resource Economics

University of California, Berkeley

Berkeley, CA 94720

kennethlee@berkeley.edu

Edward Miguel

Department of Economics

University of California, Berkeley

530 Evans Hall \#3880

Berkeley, CA 94720

and NBER

emiguel@econ.berkeley.edu
Catherine Wolfram

Haas School of Business

University of California, Berkeley

Berkeley, CA 94720-1900

and NBER

wolfram@haas.berkeley.edu

A randomized controlled trials registry entry is available at https://www.socialscienceregistry.org/trials/350 A online appendix is available at http://www.nber.org/data-appendix/w22292 


\section{INTRODUCTION}

Investments in infrastructure, including transportation, water and sanitation, telecommunications, and electricity systems, are primary targets for international development assistance. In 2015, for example, the World Bank directed a third of its global lending portfolio to infrastructure. ${ }^{1}$ The basic economics of these types of investments-which tend to involve high fixed costs, relatively low marginal costs, and long investment horizons - can justify government investment, ownership, and subsequent regulation. While development economists have recently begun to measure the economic impacts of various types of infrastructure, including transportation (Donaldson 2013; Faber 2014), water and sanitation (Devoto et al. 2012; Patil et al. 2014), telecommunications (Jensen 2007; Aker 2010), and electricity systems (Dinkelman 2011; Lipscomb, Mobarak, and Barham 2013; Barron and Torero 2015; Burlig and Preonas 2016; Chakravorty, Emerick, and Ravago 2016), there remains limited empirical evidence that links the demand-side and supply-side economics of infrastructure investments, in part due to methodological challenges. For instance, in many settings it is not only challenging to identify exogenous sources of variation in the presence of infrastructure, but also difficult to obtain detailed data on particular infrastructure extension projects.

In this paper, we analyze the economics of rural electrification. We present experimental evidence on both the demand-side and supply-side of electrification, specifically, household connections to the electric grid. Our study setting is 150 rural communities in Kenya, a country where grid coverage is rapidly expanding. In partnership with Kenya's Rural Electrification Authority (REA), we provided randomly selected clusters of households with an opportunity to connect to the grid at subsidized prices. The intervention generated exogenous variation both in the price of a grid connection, and in the scale of each local construction project. As a result, we are able to estimate both the demand curve for grid connections among households and, in a methodological innovation of the current study, the average and marginal cost curves associated with household grid connection projects of varying sizes. We then compare the demand and cost curves to begin to assess the welfare implications of mass rural electrification.

\footnotetext{
${ }^{1}$ Based on The World Bank Annual Report 2015, available at: http://www.worldbank.org/en/about/annual-report. During the 2015 fiscal year, the World Bank allocated \$14.4 billion (34 percent of total lending) towards its Energy and Mining, Transportation, and Water, Sanitation, and Flood Protection sectors. During the 2014 fiscal year, the comparable figure was even higher, at 44 percent.
} 
We find that household demand for grid connections in our data is lower than predicted, even at high subsidy rates. For example, lowering the connection price by 57 percent (relative to the prevailing price) increases demand by less than 25 percentage points. The cost of supplying these connections, however, is very high, even at universal community coverage when the benefits of the economies of scale are attained. As a result, the estimated consumer surplus from grid connections is far less than the total connection cost at all coverage levels, amounting to less than one quarter of total costs. These findings point to a perhaps unexpected conclusion, namely, that rural household electrification may reduce welfare in our setting. We then consider a variety of explanations for this finding, and present empirical evidence on the role of excess costs from leakage during construction, and reduced demand due to bureaucratic red tape, low grid reliability, and credit constraints, and more speculatively, any unaccounted for spillovers.

Electricity systems serve as canonical examples of natural monopolies in microeconomics textbooks. Empirical estimates in the literature date back to Christensen and Greene (1976), who examine economies of scale in electricity generation. ${ }^{2}$ In recent decades, initiatives to restructure electricity markets around the world have been motivated by the view that while economies of scale are limited in generation, the transmission and distribution of electricity continue to exhibit standard characteristics of natural monopolies (Joskow 2000).

We differentiate between two separate components of electricity distribution. First, there is an access component, which consists of physically extending and connecting households to the grid, and is the subject of this paper. Second, there is a service component, which consists of the ongoing provision of electricity. There is some evidence of economies of scale in both of these areas. Engineering studies, for example, show how the costs of grid extension may vary depending on settlement patterns (Zvoleff et al. 2009) or can be reduced through the application of spatial electricity planning models (Parshall et al. 2009). With regards to electricity services, data from municipal utilities has been used to demonstrate increasing returns to scale, particularly in administrative functions such as maintenance and billing (Yatchew 2000). While recent papers have examined the demand for rural electrification using both survey (Abdullah and Jeanty 2011) and experimental variation (Bernard and Torero 2015; Barron and Torero 2015), our study is the first to our knowledge to combine experimental estimates on both the

\footnotetext{
${ }^{2}$ Christensen and Greene (1976) find that while substantial economies of scale in production existed in 1955, by 1970 most U.S. electricity generation occurred in the "flat" region of the average total cost curve.
} 
demand for and costs of grid extensions. By combining these elements, we contribute to ongoing debates regarding the economics of rural household electrification.

In Sub-Saharan Africa, over 600 million people currently live without electricity (IEA 2014). In recent years, achieving universal access to modern energy has become a primary goal for policymakers, non-governmental organizations, and international donors. In 2013, for example, U.S. President Barack Obama launched his signature multi-billion dollar foreign aid initiative, Power Africa, announcing the goal of adding 60 million new connections throughout Sub-Saharan Africa. The United Nations Sustainable Development Goals include, "access to affordable, reliable, sustainable and modern energy for all." ${ }^{3}$ In Kenya, the government has recently invested heavily in expanding the electric grid to rural areas, and even though the rural household electrification rate remains low (at roughly 5 percent), the majority of households are now "under grid," or within connecting distance of a low-voltage line (Lee et al. 2016). ${ }^{4}$ As a result, "last-mile" grid connectivity has recently emerged as a political priority in Kenya.

At the macroeconomic level, the correlation between energy consumption and economic development is strong, and it is widely agreed that access to a well-functioning energy sector is critical for sustained economic growth. There is little evidence, however, on how energy drives poverty reduction, and, for example, how investments in industrial energy access compare to the economic impacts of electrifying rural households. For rural communities, there are also active debates about whether increases in energy access should be driven mainly by connections to the grid or via distributed solutions, such as solar lanterns and solar home systems. ${ }^{5}$ In this paper, we present some of the first empirical evidence on the economics of, and implementation challenges surrounding, electric grid investments in low-income regions.

Although we find that the estimated consumer surplus from household grid connections is substantially less than the total connection cost at all coverage levels, universal access to

\footnotetext{
${ }^{3}$ See http://www.un.org/sustainabledevelopment/energy/ for further details.

${ }^{4}$ According to the 2009 Kenya Population and Housing Census, available at http://www.knbs.or.ke, 5.1 percent of rural households in Kenya used electricity as the main type of lighting.

${ }^{5}$ Deichmann et al. (2010), for example, utilize a spatial planning model to suggest that for the majority of households in Sub-Saharan Africa, decentralized solutions are unlikely to be cheaper than the grid. Writing at the Breakthrough Institute, Caine et al. (2014) point out that, "whatever the short-term benefit, a narrow focus on household energy and the advocacy of small-scale energy sources like solar home systems can, in fact, make it more difficult to meet the soaring increase in energy demand associated with moving out of extreme poverty." In contrast, Craine, Mills, and Guay (2014) at the Sierra Club argue that off-grid systems are an important first step up the "energy ladder" and that basic energy services (such as lighting and mobile phone charging) must first be available before households further expand their energy consumption; see Lee, Miguel, and Wolfram (2016) for a discussion.
} 
electricity may still increase social welfare. For example, mass electrification might transform rural life in several ways: with electricity, individuals may be exposed to more media and information, might participate more actively in public life and generate improvements in the political system or public policy, and children with electricity in their homes could study more and be more likely to obtain work outside of rural subsistence agriculture later in life. However, these types of social, political and long-run economic effects have not been the main focus of electrification impact evaluations to date. Researchers and policymakers might need to focus on such outcomes in order to justify rural electrification as a development policy priority, given the small consumer surplus from electrifying rural households (relative to cost) that we estimate.

The remainder of this paper is organized as follows. Section II identifies the various natural monopoly scenarios that are empirically tested in our study; Section III discusses rural electrification in Kenya; Section IV describes the experimental design; Section V presents the main empirical results; Section VI discusses the institutional and implementation challenges to rural electrification, and their implications; and the final section concludes.

\section{THEORETICAL FRAMEWORK}

In the classic definition, an industry is a natural monopoly if the production of a particular good or service by a single firm minimizes cost (Viscusi, Vernon, Harrington 2005). More advanced treatments elaborate on the concept of subadditive costs, which extend the definition to multiproduct firms (Baumol 1977). Some textbook treatments point out that real world examples involve physical distribution networks, and specifically cite water, telecommunications and electric power (Samuelson and Nordhaus 1998; Carlton and Perloff 2005; Mankiw 2011).

\section{A. Standard model}

We consider the case of an electric utility that provides communities of households with connections to the grid. In order to supply these connections, the utility incurs a fixed cost to build a low-voltage (LV) trunk network of poles and wires within each community. In the standard model, illustrated in Figure 1, Panel A, the electricity distribution utility is a natural monopoly facing high fixed costs, constant or declining marginal costs, and a downward-sloping average total cost curve. As community coverage increases, the marginal cost of connecting an additional household should decrease as the distance to the network declines. At high coverage 
levels, the marginal cost is essentially the cost of a drop-down service cable that connects each household to the LV network. ${ }^{6}$ Household demand for a grid connection reflects expectations about the difference between the consumer surplus from electricity consumption and the price of monthly electricity service.

The social planner's solution is to set the connection price equal to the level where the demand curve intersects the marginal cost curve $\left(p^{\prime}\right)$. Due to the natural monopoly characteristics of the industry, the utility is unable to cover its costs at this price, and the social planner must subsidize the electric utility to make up the difference. In Panel A, total social surplus from the electricity distribution system is positive at price $\mathrm{p}^{\prime}$ since the area under the demand curve is greater than the total cost, represented by rectangle with height $\mathrm{c}^{\prime}$ and width $\mathrm{d}^{\prime}$.

\section{B. Alternative scenarios and potential externalities from grid connections}

We illustrate an alternative scenario in Figure 1, Panel B. Here, the natural monopolist faces high costs relative to demand. The marginal cost curve does not intersect the demand curve and a subsidized mass electrification program reduces social welfare. In this case, mass electrification appears unlikely to be an attractive policy.

In Panel C, we maintain the same demand and cost curves as in Panel B, but illustrate a case in which the social demand curve (D') lies above the private demand curve (D). There may be positive externalities (spillovers) from private grid connections, especially in communities with strong social ties, where connected households share the benefits of power with their neighbors. In rural Kenya, for instance, it is common for people to spend some time in the homes of neighbors who have electricity, watching television, charging mobile phones, and enjoying better quality lighting in the evening. Another factor that could contribute to a gap between $\mathrm{D}$ and $\mathrm{D}^{\prime}$ is the possibility that households have higher inter-temporal discount rates than government policymakers. For example, if electrification allows children to study more and increases future earnings, there may be a gap if parents discount their children's future earnings more than a social planner. Further, demand may be low due to market failures, such as credit constraints or a lack of information about the long-run private benefits of a connection; the social demand curve would reflect the willingness to pay for grid connections if these issues were resolved. In general, if $\mathrm{D}^{\prime}$ lies above $\mathrm{D}$, there may be a price at which the consumer surplus (the area underneath $\mathrm{D}^{\prime}$ ) will exceed total costs.

${ }^{6}$ This is particularly the case if households are sampled randomly and connected, as in the experiment we study. 
Which of these cases best fits the data? In this paper, we trace out the natural monopoly cost curves using experimental variation in the connection price and in the scale of each construction project. The estimated curves correspond to the segments of Figure 1 that range between the pre-existing rural household electrification rate level, which is roughly 5 percent at baseline in our data, and full community coverage $(\mathrm{d}=1)$. This is the policy relevant range for governments considering subsidized mass rural connection programs.

One type of externality that we do not consider is the negative spillover from greater energy consumption, due to higher $\mathrm{CO}_{2}$ emissions and other forms of environmental pollution. These would shift the total social cost curve up, making mass electrification less desirable. In the next section, we discuss aspects of electricity generation in Kenya that make these issues less of a concern in our setting than they often are elsewhere.

\section{RURAL ELECTRIFICATION IN KENYA}

Kenya has a relatively "green" electricity grid, with most energy generated through hydropower and geothermal plants, and with fossil fuels representing just one third of total installed electricity generation capacity, which currently stands at 2,295 megawatts. Installed capacity is projected to increase tenfold by the year 2031, with the proportion of electricity generated using fossil fuels remaining roughly the same over time. ${ }^{7}$ Thus Kenya appears poised to substantially increase rural energy access by relying largely on non-fossil fuel energy sources.

In recent years, there has been a dramatic increase in the coverage of the electric grid. For instance, in 2003, a mere 285 public secondary schools across the country had electricity connections, while by November 2012, Kenyan newspapers projected that 100 percent of the country's 8,436 secondary schools would soon be connected. The driving force behind this push was the creation of REA, a government agency established in 2007 to accelerate the pace of rural electrification. ${ }^{8}$ REA's strategy has been to prioritize the connection of three major types of rural public facilities, namely, market centers, secondary schools and health clinics. Under this approach, public facilities not only benefited from electricity but also served as community

\footnotetext{
${ }^{7}$ Specifically, in 2015, total installed capacity was 2,295 MW and consisted primarily of hydro (36.0 percent), fossil fuels (35.4 percent), and geothermal (25.8 percent) sources. Based on government planning reports (also referred to as "Vision 2030"), total installed capacity is expected to reach 21,620 MW by 2031, with fossil fuels (e.g., thermal, medium-speed diesel, and geothermal-natural gas) representing 32.4 percent of the total. Many other African countries generate similar shares of electricity from non-fossil fuel sources (Lee, Miguel, and Wolfram 2016). ${ }^{8}$ Prior to the creation of REA, rural electrification was the joint responsibility of the Ministry of Energy and Petroleum and Kenya Power, the country's regulated monopoly transmission, distribution and retail company.
} 
connection points, bringing previously off-grid homes and businesses within close reach of the grid. In June 2014, REA announced that 89 percent of the country's 23,167 identified public facilities had been electrified. This expansion had come at a substantial cost to the government, at over $\$ 100$ million per year. The national household electrification rate, however, remained relatively low at 32 percent, with far lower rates in rural areas. ${ }^{9}$ Given the widespread grid coverage, the Ministry of Energy and Petroleum identified last-mile connections for "under grid" households as the most promising strategy to reach universal access to power.

During the decade leading up to the period of this study, any household in Kenya within 600 meters of an electric transformer could apply for an electricity connection at a fixed price of $\$ 398$ (35,000 KES). ${ }^{10}$ The fixed price had initially been set in 2004 and was intended to cover the cost of building infrastructure in rural areas. As REA worked to expand grid coverage, the connection price emerged as a major public issue in 2012, appearing with regular frequency in national newspapers and policy discussions. The fixed price seemed "too high" for many if not most poor, rural households to afford. However, Kenya Power, the national electricity utility, estimated the cost of supplying a single connection in a grid-covered area to be $\$ 1,435$, which vastly exceeded the household charge. After the government rejected its proposal to increase the price to $\$ 796$ (70,000 KES) in April 2013, Kenya Power initially announced that it would no longer supply grid connections in rural areas at all, limiting supply to households that were a single service cable away from an LV line. As a result, the government agreed to temporarily provide Kenya Power with subsidies to cover any excess costs incurred, allowing the expansion of rural grid connections to continue at the same $\$ 398$ price as before. In February 2014, the government ended these subsidies to Kenya Power, and it was again reported that the price would increase to $\$ 796$. Ultimately, the $\$ 398$ fixed price remained in place for households within 600 meters of a transformer throughout our study period, from late-2013 to early-2015.

The government announced in May 2015 (after our primary data collection activities) that it had secured \$364 million-primarily from the African Development Bank and the World Bank - to launch the Last Mile Connectivity Project (LMCP), a subsidized mass electrification program that plans to eventually connect four million "under grid" households, and that once

\footnotetext{
${ }^{9}$ REA provided us with estimates of the proportion of public facilities electrified (June 2014), the national electrification rate (June 2014), and overall REA investments (between 2012 and June 2015).

${ }^{10}$ All Kenya Shilling (KES) figures are converted into U.S. dollars at the 2014 average exchange rate of 87.94 KES/USD. The fixed price of 35,000 KES was set in 2004 in order to reduce the uncertainty surrounding cost-based pricing. Anecdotally, there were concerns that some staff had lowered the cost-based price in exchange for a bribe.
} 
launched, the program would lower the fixed price substantially to $\$ 171$ (15,000 KES). This new price was based on the Ministry of Energy and Petroleum's internal predictions for take-up across all rural areas, and was revealed for the first time to the public in May 2015. For households that were unable to afford this price, a financing plan would also be put in place, allowing households to slowly pay for their connections over time, although few details have been provided. ${ }^{11}$ Our study, which is described in the next section, takes place during the tail end of the decade-long \$398 price regime, before the announcement of the planned LMCP program.

\section{EXPERIMENTAL DESIGN AND DATA}

\section{A. Sample selection}

This field experiment takes place in 150 "transformer communities" in Busia and Siaya, two counties that are broadly representative of rural Kenya in terms of electrification rates and economic development, and where population density is fairly high. ${ }^{12}$ Each transformer community is defined as the group of all households located within 600 meters of a secondary electricity distribution (low-voltage, LV) transformer, the official distance threshold that Kenya Power established for connecting buildings to the grid at the standard price.

The list of communities was sampled in close cooperation with REA. In August 2013, local representatives of REA provided us with the master list of all 241 unique REA projectscentered on the electrification of a market, secondary school, or health clinic - consisting of roughly 370 individual transformers spread across Busia and Siaya. ${ }^{13}$ Using this list, we randomly selected 150 transformers, subject to the conditions that the distance between any two transformers was at least $1.6 \mathrm{~km}$ (1 mile), and each transformer represented a unique REA project. In our final sample, there are 85 and 65 transformers in Busia and Siaya, respectively. ${ }^{14}$

Between September and December 2013, teams of surveyors visited each of the 150 transformer communities to conduct a census of the universe of households within 600 meters of the central transformer. This database, consisting of 12,001 unconnected households in total,

\footnotetext{
${ }^{11}$ At the time of writing this paper, the government had not yet begun any LMCP electricity connections.

${ }^{12}$ In Appendix Table A1, we use national census data to compare Busia and Siaya to all other counties in Kenya.

The sample region is more densely populated than most other rural areas, but is broadly representative of - or lags just behind - other regions in terms of basic education, income proxies, and grid coverage.

13 Since REA has been the main driver of rural electrification, this master list reflects the universe of rural communities in which there is a possibility of connecting to the grid in these two counties.

${ }^{14}$ Appendix Figure A1 maps the communities in our sample. Appendix Note A1 provides further details.
} 
served as the sampling frame for our study. At the time of the census, 94.5 percent of households remained unconnected despite being "under grid" (Lee et al. 2016).

We present a map of a fairly typical (in terms of residential density) transformer community in our sample in Figure 2, illustrating the degree to which unconnected households are within close proximity of an LV line. Although population density in our setting is high, the average minimum distance between structures is 52.8 meters. These distances make illegal connections quite costly, since local pole infrastructure would need to be built in order to "tap" into nearby lines. In practice, the number of illegal connections is negligible in our sample.

For each unconnected household, we calculated the shortest (straight-line) distance to an LV line, approximated by either a connected structure or a transformer. To limit construction costs, REA requested that we limit our sampling frame to the 84.9 percent of these households that were no more than 400 meters away from a connected structure or a transformer. Applying this threshold, we randomly selected, enrolled, and surveyed 2,289 "under grid" households, or roughly 15 households per community.

\section{B. Experimental design and implementation}

We illustrate the experimental design in Figure 3. Between February and August 2014, we administered a baseline survey to the 2,289 study households. In addition, we collected baseline data for 215 already connected households - or 30.5 percent of the universe of households observed to be connected to the grid at the time of the census-sampling up to four connected households in each community, wherever possible. See Appendix Note A2 for details.

In April 2014, we randomly divided the sample of transformer communities into treatment and control groups of equal size, stratifying the randomization process to ensure balance across county, market status, and whether the transformer installation was funded early on (namely, between 2008 and 2010). The 75 treatment communities were then randomly assigned into one of three subsidy treatment arms of equal size. Following baseline survey activities in each community, between May and August 2014, each treatment household received an official letter from REA describing a time-limited opportunity to connect to the grid at a subsidized price. ${ }^{15}$ The treatment and control groups are characterized as follows:

\footnotetext{
${ }^{15}$ We provide an example of this letter in Appendix Figure A2.
} 
1. High subsidy arm: 380 unconnected households in 25 communities are offered a $\$ 398$ (100 percent) subsidy, resulting in an effective price of $\$ 0$.

2. Medium subsidy arm: 379 unconnected households in 25 communities are offered a $\$ 227$ (57 percent) subsidy, resulting in an effective price of $\$ 171$.

3. Low subsidy arm: 380 unconnected households in 25 communities are offered a $\$ 114$ (29 percent) subsidy, resulting in an effective price of $\$ 284$.

4. Control group: 1,150 unconnected households in 75 communities receive no subsidy and face the regular connection price of $\$ 398$.

Households were given eight weeks to accept the offer and deposit an amount equal to the effective connection price (i.e., actual price less the subsidy amount) into REA's bank account. ${ }^{16}$ In order to prevent transfers of the offer between households, the offer was only valid for the primary residential structure, identified by the GPS coordinates captured during the baseline survey. All treatment households were given a reminder phone call two weeks prior to the expiry date of the offer. At the end of the eight-week period, enumerators visited each household to collect copies of bank receipts to verify that payments had been made.

Treatment households also received an opportunity to install a basic and certified household wiring solution (a "ready-board") in their homes at no additional cost. Each readyboard — valued at roughly $\$ 34$ per unit—featured a single light bulb socket, two power outlets, and two miniature circuit breakers. ${ }^{17}$ Finally, each connected household received a prepaid electricity meter at no additional charge from Kenya Power.

We registered a pre-analysis plan, which is attached to the Appendix and is available at https://www.socialscienceregistry.org/trials/350, on the AEA RCT Registry in July 2014 while most treatment offers were still pending and before analysis of any grid connection take-up data (Casey, Glennerster, and Miguel 2012).

After verifying payments, we provided REA with a list of households that would be connected. This initiated a lengthy process to complete the design, contracting, construction, and metering of grid connections: the first household was metered in September 2014, the average connection time was seven months, and the final household was metered over a year later, in October 2015. Additional details are discussed in Section VI.B below.

\footnotetext{
${ }^{16}$ In Kenya, one does not need a bank account in order to deposit funds into a specified bank account.

${ }^{17}$ The ready-board was designed and produced for the project by Power Technics, an electronic supplies manufacturer in Nairobi. A diagram of the Power Technics ready-board is presented in Appendix Figure A3.
} 


\section{Data}

The analysis combines survey, experimental, and administrative data, collected and compiled between August 2013 and October 2015. The datasets include:

1. Community characteristics data $(n=150)$ covering all 150 transformer communities in our sample, including estimates of community population (i.e., within 600 meters of a central transformer), baseline electrification rates, year of community electrification (i.e., transformer installation), distance to REA warehouse, and average land gradient. ${ }^{18}$

2. Household survey data $(n=2,504)$ from the baseline survey, consisting of information on respondent and household characteristics, living standards, time use, recent energy consumption, and stated demand (contingent valuation) for an electricity connection.

3. Experimental demand data $(\mathrm{n}=2,289)$ consisting of take-up decisions for the 1,139 treatment households (collected between May and August 2014) and 1,150 control households (collected between January and March 2015) in our sample.

4. Administrative cost data $(\mathrm{n}=77)$ supplied by REA including both the budgeted and invoiced costs for each project. For each community in which the project delivered an electricity connection $(n=62)$, we received data on the number of poles and service lines, length of LV lines, and design, labor and transportation costs. Using these data, we calculate the average total cost per household for each community. In addition, REA provided us with cost estimates for higher levels of coverage (i.e., at 60, 80, and 100 percent of the community connected) for a subset of the high subsidy arm communities $(\mathrm{n}=15) .{ }^{19}$ Combining the actual sample and designed communities data $(\mathrm{n}=77)$ enables us to trace out the cost curve at all coverage levels.

\section{Baseline characteristics}

Table 1 summarizes differences between unconnected and connected households at baseline. Connected households are characterized by higher living standards across almost all

\footnotetext{
${ }^{18}$ Following Dinkelman (2011), gradient data is from the 90-meter Shuttle Radar Topography Mission (SRTM) Global Digital Elevation Model (www.landcover.org). Gradient is measured in degrees from 0 (flat) to 90 (vertical).

${ }^{19}$ REA followed the same costing methodology (e.g., the same personnel visited the field sites to design the LV network and estimate the costs) applied to the communities in which we delivered an electricity connection, to ensure comparability between budgeted estimates for "sample" and "designed" communities, as discussed below.
} 
proxies for income. ${ }^{20}$ In particular, these households have higher quality walls (made of brick, cement, or stone, rather than the typical mud walls), have higher monthly basic energy expenditures, and own more land and assets including livestock, household goods (e.g., furniture), and electrical appliances.

The vast majority of unconnected households in our sample (92.4 percent) rely on kerosene as their primary source of lighting, while only 6 and 3 percent of unconnected households own solar lanterns and solar home systems, respectively. These figures point to an opportunity to increase rural energy access through distributed solar systems. Based on current technologies, however, grid connections and distributed solar are vastly different in terms of potential applications. Grid connections allow households to use a far wider range of appliances, and in particular, those that require more power. In Appendix Figure A6, we show that at baseline, many unconnected households owned mobile phones and radios, the types of lowerwattage appliances that could be powered using standard solar home systems. In contrast, connected households were the primary owners of higher-wattage appliances, such as televisions and irons, which are also some of the most desired appliances but which home solar systems typically cannot support (Lee, Miguel, and Wolfram 2016).

In Appendix Table A2, we report baseline statistics for the control group. On average, 63 percent of respondents are female, just 14 percent have attended secondary school, 66 percent are married, and, in terms of occupation, 77 percent are primarily farmers. Households have 5.3 members on average, of which 3.0 are ages 18 and under. These are overwhelmingly poor households, as evidenced by the fact that only 15 percent have high-quality walls. Households spend $\$ 5.55$ per month on (non-charcoal) energy sources, primarily kerosene. ${ }^{21}$

\footnotetext{
${ }^{20}$ These patterns are consistent with the stated reasons for why households remain unconnected to electricity. In Appendix Figure A4, we show that, at baseline, 95.5 percent of households cited the high connection price as the primary barrier to connectivity. The second and third most cited reasons - which were the high cost of internal wiring (10.2 percent) and the high monthly cost (3.6 percent) - are also related to costs. Note that no households said they were unconnected because they were waiting for a lower connection price, or a government-subsidized rural electrification program. In fact, prior to our intervention, there were concerns that the price would increase. In Appendix Figure A5, we present a timeline of project milestones and connection price-related news reports over the period of the study. Furthermore, during our intervention, 397 households provided a reason for why they had declined a subsidized offer and not one cited the possibility of a lower future price. Taken together, these factors alleviate concerns that households were anticipating a subsidized government mass electrification program.

${ }^{21}$ In June 2014, the standard electricity tariff for small households was roughly 2.8 cents per $\mathrm{kWh}$. Taking into consideration fixed charges and other adjustments, $\$ 5.55$ per month translates into roughly $30 \mathrm{kWh}$ of electricity consumption, which is enough to power basic lighting, television, and fan appliances, each day of the month.
} 
We test for balance across treatment arms by regressing a set of household and community characteristics on indicators for the three subsidy levels, and also conduct $F$-tests that all treatment coefficients are equal to zero. For the 20 household-level and two community-level variables analyzed, F-statistics are significant at the 5 percent level for only two variables - a binary variable indicating whether the respondent was able to correctly identify the presidents of Tanzania, Uganda, and the United States (a measure of political awareness) and monthly (noncharcoal) energy spending, indicating that the randomization created largely comparable groups.

\section{RESUlTS}

\section{A. Estimating the demand for electricity connections}

In Figure 4, we plot the experimental results on the demand for grid connections. We find that take-up of a free grid connection offer is nearly universal, but demand falls sharply with price, and is close to zero among the low subsidy treatment group, as well as in the control group, which did not receive any subsidies. In Panel A, we present the experimental results and also compare them to two distinct "priors" on demand. The first curve (long-dashed line, black squares) plots our research team's predictions for take-up. These predictions were recorded in our 2014 pre-analysis plan and reflect our "best guess" of the demand curve; they were generated in part due to our need to make realistic budget predictions (since project grants financed the subsidies that households received). The second curve (long-dashed line, grey squares) plots the Ministry of Energy and Petroleum's internal predictions for take-up in rural Kenya. The government demand curve-which we learned of in early-2015 via a government report—was developed independently of our project and served as the justification for the planned LMCP price of $\$ 171$ (15,000 KES). A key finding is that, even at generous subsidy levels, actual takeup is significantly lower than predicted by the government or by our team. ${ }^{22}$ In Panel B, we show that households with high-quality walls had substantially higher take-up rates in the medium and low subsidy arms, suggesting that demand increases at higher incomes.

In Table 2, we report the results of estimating the following regression equation:

$$
y_{i c}=\alpha+\beta_{1} T_{c}^{L}+\beta_{2} T_{c}^{M}+\beta_{3} T_{c}^{H}+X^{\prime}{ }_{c} \gamma+X^{\prime}{ }_{i c} \lambda+\epsilon_{i c}
$$

\footnotetext{
${ }^{22}$ The government report projected take-up in rural areas nationally, rather than in our study region alone, and this is one possible source of the discrepancy, i.e., take-up might be higher (or lower) in other Kenyan regions.
} 
where $y_{i c}$ is an indicator variable reflecting the take-up decision for household $i$ in transformer community $c$. The binary variables $T_{c}^{L}, T_{c}^{M}$, and $T_{c}^{H}$ indicate whether community $c$ was randomly assigned into the low, medium, or high subsidy arm, respectively, and the coefficients $\beta_{1}, \beta_{2}$, and $\beta_{3}$ capture the subsidy impacts on take-up. ${ }^{23}$ Following Bruhn and McKenzie (2009), we include a vector of community-level characteristics, $X_{c}$, containing variables used for stratification during randomization (see Section IV.B). In addition, we include a vector of baseline household-level characteristics, $X_{i c}$, containing standard covariates (specified in our preanalysis plan) that may also predict take-up, including household size, the number of chickens owned, respondent age, high-quality walls, and whether the respondent attended secondary school, is not a farmer, uses a bank account, engages in business or self-employment, and is a senior citizen. Standard errors are clustered by community, the unit of randomization.

The results of estimating equation 1 are reported in Table 2, column 1. All three subsidy levels lead to significant increases in take-up: the 100 percent subsidy increases the likelihood of take-up by roughly 95 percentage points, and the effects of the partial 57 and 29 percent subsidies are much smaller, at 23 and 6 percentage points, respectively. Columns 2 to 4 include interactions between the treatment indicators and correlates of household economic status, including whether the household has high-quality walls, and the respondent attended secondary school and is not a farmer. Take-up in treatment communities is differentially higher in the low and medium subsidy arms for households with more educated and wealthier respondents. ${ }^{24}$

Based on the findings in Bernard and Torero (2015), one might expect take-up to be higher in areas where electricity is more prevalent if, as they argue, exposure to households with an electricity connection leads individuals to better understand its benefits and value it more. Yet when we include an interaction with the baseline community electrification rate in column 5 , or an interaction with the proportion of neighboring households within 200 meters connected to electricity at baseline (column 6), we find no meaningful interaction effects. ${ }^{25}$

\footnotetext{
${ }^{23} \mathrm{We}$ focus on this non-parametric specification after rejecting the null hypothesis that the treatment coefficients are linear in the subsidy amount $(F$-statistic $=23.03)$, a choice we specified in our pre-analysis plan.

${ }^{24}$ In Appendix Table A3, we compare the characteristics of households choosing to take up electricity across treatment arms. Households that paid more for an electricity connection (i.e., the low subsidy arm households) are wealthier on average than those who paid nothing (high subsidy), i.e., they are better educated, more likely to have bank accounts, live in larger households with high-quality walls, spend more on energy, and have more assets. In Appendix Tables A4A-A4B, we report all regressions specified in our pre-analysis plan, for completeness.

${ }^{25}$ Of course, this does not rule out the possibility of a differential effect at higher levels of electrification, since baseline household electrification rates are generally low in our sample of communities (the interquartile range is 1.8 to 7.8 percent). Also, since community-level characteristics, such as income, are likely positively correlated across
} 


\section{B. Estimating the economies of scale in electricity grid extension}

An immediate consequence of the downward-sloping demand curve estimated above is that the randomized price offers generate exogenous variation in the proportion of households in a community that are connected as part of the same construction project. This novel design feature allows us to experimentally assess the economies of scale in electricity grid extension.

In Table 3, we report the results of estimating the impact of the number of connections, $M_{c}$, and a quadratic term, $M_{c}^{2}$, on the average total cost per connection ("ATC"), $\Gamma_{c}$. Specifically, we estimate the regression equation:

$$
\Gamma_{c}=\pi_{0}+\pi_{1} M_{c}+\pi_{2} M_{c}^{2}+V_{c}^{\prime} \mu+\eta_{c}
$$

In the pre-analysis plan, we hypothesized that the ATC would fall with more connections (i.e. $\pi_{1}<0$ ), but at a diminishing rate (i.e. $\pi_{2}>0$ ), and we test this for two samples. The first sample (columns 1 to 3 ) consists of the 62 treatment communities in which we observed nonzero demand. The second sample (columns 4 to 7 ) also includes the additional 15 sites that were designed and budgeted for us by REA at even higher coverage levels (up to 100 percent). In columns $2,3,6$, and 7 , we also include a vector of community-level characteristics, $V_{c}$, which contains the community-level variables in $X_{c}$ described above, as well as the round-trip distance between community $c$ and the regional REA warehouse in Kisumu (a determinant of project transport costs), and the average land gradient for each 600-meter radius transformer community. Column 3 reports the results of an instrumental variables specification in which the experimental subsidy terms, $T_{c}^{M}$ and $T_{c}^{H}$ serve as instruments for the number of connections $\left(M_{c}\right.$ and $\left.M_{c}^{2}\right){ }^{26}$

The mean cost per connection in the data is $\$ 1,813 .{ }^{27}$ The coefficients on $M_{c}$ and $M_{c}^{2}$ are both statistically significant and large with the hypothesized signs, and are stable across the OLS and IV specifications. Within the domain of the first sample (which ranges from 1 to 16 connections per community), increasing project scale by a single household decreases the ATC by roughly $\$ 500$, and costs reach a minimum at approximately 11 households. Within the second

households, the lack of statistically significant coefficients may reflect the joint impacts of negative take-up spillovers and positively correlated take-up decisions; future research could usefully explore these issues.

${ }^{26}$ In our pre-analysis plan, we specified an IV regression that included three instrumented variables, $M_{c}, M_{c}^{2}$, and $M_{c}^{3}$. We dropped the third term because we were unable to acquire cost estimates for the control communities, which limited our sample to the treatment communities, and effectively limited our set of instruments to $T_{c}^{M}$ and $T_{c}^{H}$.

${ }^{27}$ While this may seem high, recall that it is closely in line with Kenya Power's estimate of $\$ 1,435$ per rural connection, as well as an internal estimate of $\$ 1,602$ provided by the Ministry of Energy and Petroleum. 
sample including the designed communities (which ranges from 1 to 85 connections), the estimated $\pi_{1}$ drops to roughly $\$ 84$ and costs reach a minimum at approximately 55 households.

In column 5 , we estimate the ATC as a quadratic function of community coverage, $Q_{c}$, which we define as the proportion of initially unconnected households in the community that become connected. We carry out this transformation (focusing on $Q_{c}$ instead of $M_{c}$ ) because estimating the ATC in terms of community coverage will allow for a direct comparison of the demand curve to the cost curves in Section V.C below. In Figure 5, Panel A we plot the fitted curve from this regression on a scatterplot of ATC and community coverage. The quadratic function does not appear to provide a particularly good fit to the data visually: it predicts considerably lower costs at intermediate coverage levels while overstating them at nearly universal coverage, in large part because the functional form specified in the pre-analysis plan failed to include a fixed cost at the community level. We therefore estimate an alternative functional form for ATC featuring a fixed community cost and linear marginal costs:

$$
\Gamma_{c}=\frac{b_{0}}{Q_{c}}+b_{1}+b_{2} Q_{c}
$$

The nonlinear estimation of equation 3 yields coefficient estimates (and standard errors) of $b_{0}=2287.8$ (s.e. 322.8 ) for the fixed cost, $b_{1}=1244.3$ (s.e. 159.0), and $b_{2}=-6.1$ (s.e. 3.4). We plot the predicted values from this nonlinear estimation in Figure 5, Panel B, and then take the derivative of the total cost function (which is obtained by first multiplying equation 3 by $Q_{c}$ ) to estimate the linear marginal cost function:

$$
M C_{c}=b_{1}+2 b_{2} Q_{c}
$$

While this choice of functional form may appear somewhat arbitrary, we believe that imposing linear marginal costs is both economically intuitive (e.g., as coverage increases, the marginal cost of connecting an additional household decreases) and also closely matches the observed data. Regardless of the exact functional form, though, average costs decline in the number of households connected, as in the textbook natural monopoly case. ${ }^{28}$ While there are strong initial economies of scale, we also document that the incremental cost savings appear to decline at higher levels of community coverage, and the estimates imply an average cost of approximately $\$ 658$ per connection at levels near universal coverage $\left(Q_{c}=100\right)$.

\footnotetext{
${ }^{28}$ In Appendix Figure A8, we compare alternative functional forms, and the same conclusions hold across all cases.
} 
In communities with larger populations, the higher density of households may potentially translate into a larger impact of scale on ATC. In Table 3, column 7, we include interactions between scale and community population. While there are no statistically significant effects in the limited range of densities observed in our sample, it seems plausible that per household connection costs could be higher in other parts of rural Kenya with far lower rates of residential density (as shown in Appendix Table A1). There is also no evidence that higher average land gradient is associated with higher ATC. ${ }^{29}$

\section{Social welfare calculations}

In Figure 6, we compare the experimental demand curve with the average and marginal cost curves (Panel A), and then estimate total cost and consumer surplus at full coverage (Panel B) and at partial coverage using the estimated demand at the planned government LMCP connection price (Panel C). We first focus on the revealed preference demand estimates, and discuss issues of credit constraints and informational asymmetries below in Section VI.B.

The main observation is that the estimated demand curve for an electricity connection does not intersect the estimated marginal cost curve. To illustrate, at 100 percent coverage, we estimate the total cost of connecting a community to be $\$ 55,713$ based on the mean community density of 84.7 households. In contrast, consumer surplus at this coverage level is estimated based on the demand curve to be far less, at only $\$ 12,421$, or less than one quarter the costs. The consumer surplus is substantially smaller than total connection costs at all quantity levels, in fact, suggesting that rural household electrification may reduce social welfare.

Specifically, our calculations suggest that a mass electrification program would result in a welfare loss of $\$ 43,292$ per community. ${ }^{30}$ In order to justify such a program, discounted future social welfare gains of $\$ 511$ would be required for each household in the community, above and

\footnotetext{
${ }^{29}$ Based on Dinkelman (2011), we expect land gradient to be positively correlated with ATC. In our setting, the correlation is negative. In Appendix Table A5, we expand the reported results for columns 4 and 6 in Table 3, and report the results of a specification including interactions between scale and average land gradient. While the results are counterintuitive, note that there is little variation in average land gradient in our sample, which ranges from 0.79 to 7.76 degrees. Land gradient may be an important predictor of the costs associated with extending high-voltage lines to new areas in KwaZulu-Natal, South Africa, as in the Dinkelman (2011) case. Our data suggest that it is less important in predicting the costs of grid extensions across smaller areas. In Appendix Figure A7, we compare ATC curves for low and high gradient communities and again find no visual evidence of a meaningful difference.

${ }^{30}$ To calculate consumer surplus, we estimate the area under the unobserved $[0,1.3]$ domain by projecting the slope of the demand curve in the range $[1.3,7.1]$ through the intercept. The 1.3 percent figure is the proportion of the control group that chose to connect to the grid during the study period. In Appendix Figure A9, we estimate the welfare loss under alternative demand curve assumptions. In Panel $\mathrm{C}$, the most conservative case, demand is a step function and intersects the vertical axis at $\$ 3,000$. The welfare loss is still $\$ 32,517$ per community in this case.
} 
beyond any economic or other benefits already considered by households in their own private take-up decisions. These welfare gains could take a number of possible forms, including spillovers in consumption or broader economic production.

Credit constraints, or imperfect household information about the long-run benefits of electrification, may also contribute to lower demand, issues we turn to in the next section, while negative pollution externalities could raise the social costs of grid connections.

In an alternative scenario (Panel C), we estimate the demand for and costs of a program structured like the LMCP, which plans to offer households a connection price of $\$ 171$. In this case, only 23.7 percent of households would accept the price based on our experimental estimates, and thus unless the government is willing to provide additional subsidies or possibly financing, the resulting electrification level would be low. At 23.7 percent coverage, there is an analogous welfare loss of $\$ 22,100$ per community, or $\$ 1,099$ per connected household.

\section{INSTITUTIONAL AND IMPLEMENTATION CHALLENGES}

The results in the previous section - suggesting that rural electrification may reduce social welfare - are perhaps surprising. Previous analyses have found substantial benefits from electrification (Dinkelman 2011, Lipscomb, Mobarak, and Barham 2013), though they have not compared benefits to costs. In the Philippines, Chakravorty, Emerick, and Ravago (2016) find that the physical cost of grid expansion is recovered after just a single year of realized expenditure gains. A World Bank report argues that household willingness to pay for electricity - which is calculated indirectly based on kerosene lighting expenditures - is likely to be well above the average supply cost in South Asia (World Bank 2008). The majority of these studies, however, use non-experimental variation or indirect measures of costs and benefits, and it is possible that they do not account for unobservables correlated with both electrification propensity and improved economic outcomes. In Table 1, for example, we document a strong baseline correlation between household connectivity and living standards, and this pattern is consistent with the possibility of meaningful omitted variable bias in non-experimental studies.

In this section, we consider factors that could drive down costs or drive up demand in our setting. Specifically, we present evidence on the role of excess construction costs from leakage, and reduced demand due to bureaucratic red tape, low grid reliability, credit constraints, and possibly unaccounted for spillovers in driving the social welfare results in the previous section. 


\section{A. Excess costs from leakage}

In Table 4, we report the breakdown of budgeted versus invoiced electrification costs per community. The budgeted (ex-ante) costs for each project are based on LV network drawings prepared by a team of REA engineers. ${ }^{31}$ The invoiced (ex-post) costs are based on actual final invoices submitted by local contractors, detailing the contractor components of the labor, transport, and materials that were required to complete each project. In total, it cost $\$ 585,999$ to build 101.6 kilometers of LV lines to connect 478 households through the project.

We separate costs into three categories: (1) Local network costs, which consist of lowand high-voltage cables, wooden poles and the various components required to attach cables to poles, (2) Labor and transport costs, which include the cost of network design, installation, and transportation, and (3) Service lines, which are the drop-down cables connecting the homes. ${ }^{32}$ Overall, budgeted and invoiced costs per connection were nearly identical, amounting to $\$ 1,201$ and $\$ 1,226$, respectively. In other words, contractors submitted invoices that were only 1.7 percent higher than the budgeted amount on average. The similarity between planned and actual costs provides further confidence that the connection costs for the designed communities at higher coverage levels are likely to be reasonably accurate.

These cost figures reflect the reality of grid extension in rural Kenya, but it is possible that they are higher than would ideally be the case due to leakage and other inefficiencies. Of course, leakage is common in the public sector in low income countries: Reinikka and Svenson (2004), for example, find that Ugandan schools received only 13 percent of a central government spending program. In our context, it is possible that leakage occurred during the contracting work, in the form of over-reporting labor and transport, which may be hard to verify, and substandard construction quality (e.g., using fewer materials than required). There is evidence of reallocations across the sub-categories in Table 4, despite the similarities between ex ante and ex post totals. Invoiced labor and transport costs, for example, were 12.7 percent higher in fact than expected in the plans, while invoiced local network costs were 6.5 percent lower.

We sent teams of enumerators to each treatment community to count the number of electricity poles that were actually installed, and then compare the actual number of poles to the poles included in the project designs in order to gain additional insight on leakage. We find

\footnotetext{
${ }^{31}$ An example of an LV network drawing is provided in Appendix Figure A10.

${ }^{32}$ In Table 4, we exclude the costs of metering (incurred by Kenya Power) and ready-boards. Including them would not alter the main conclusions since they are the same for all connected households and a small share of total costs.
} 
strong evidence of leakage in the form of missing electrical poles. In Figure 7, we plot the discrepancies between costs and poles by contractor, where each circle represents one of the 14 contractors participating in the project, and the size of each circle is proportional to the number of household connections supplied by that contractor. While there is minimal variation between overall ex-ante and ex-post total costs, as depicted on the horizontal axis, most contractors' projects showed large differences in the number of observed versus budgeted poles, as depicted on the vertical axis, with nearly all using fewer poles than budgeted. The number of observed poles was 21.3 percent less than the number of budgeted poles, a substantial discrepancy.

In addition to being associated with wastage of public resources, if the planned number of poles reflects accepted engineering standards (i.e., poles are roughly 50 meters apart, etc.), using fewer poles might lead to substandard service quality and even safety risks. For instance, local households may face greater injury risk due to sagging power lines between poles that are spaced too far apart, and the poles could be at greater risk of falling over. It is possible, however, that REA's designs included extra poles, perhaps anticipating that contractors would not use them all.

Labor and transport costs may also reflect leakage. Labor is typically invoiced based on the number of declared poles, and we showed above that those were inflated. Similarly, transport is invoiced based on the declared mileage of vehicles carrying construction materials. In Appendix Table A6, we analyze three highly detailed contractor invoices (for nine communities) that were made available to us. Based on this partial data, we find evidence of over-reported labor costs associated with the electricity poles, at 11.0 percent higher costs than expected, and massively over-reported transport costs: based on a comparison between the reported mileage and the travel routes between the REA warehouse and project sites suggested by Google Maps, invoiced travel costs were 32.9 percent higher than expected.

Taken together, these findings suggest that electric grid construction costs may be substantially inflated due to mismanagement and corruption in Kenya, pointing to the possibility that improved monitoring and enforcement of contractors could reduce costs and possibly improve project quality and safety. ${ }^{33}$ On the other hand, note that even with a 20 to 30 percent reduction in construction costs, mass rural household electrification would still lead to a reduction in overall social welfare based on the demand and cost estimates in Figure 6.

\footnotetext{
${ }^{33}$ To the extent costs are high because contractors are over-billing the government, leakage may simply result in a transfer across Kenyan citizens and not a social welfare loss. The social welfare implications would depend on the relative weight the social planner places on contractors, taxpayers, and rural households.
} 


\section{B. Factors contributing to lower demand for electricity connections}

We next discuss several factors that potentially contribute to lower levels of observed household demand for electricity connections, including bureaucratic red tape, low grid reliability, credit constraints, and unaccounted for positive spillovers.

Long delays in the delivery of electricity services are common in rural Kenya, and low levels of demand may be attributable, in part, to the lengthy and bureaucratic process of obtaining a connection. In our sample, it took a staggering 212 days on average to complete each community project. The World Bank similarly estimates that in practice it takes roughly 110 days to connect new business customers to the electricity grid in Kenya (World Bank 2016).

Figure 8 summarizes the time required to complete each major phase associated with obtaining a rural household grid connection in Kenya. The timeline is presented in two panels; Panel A reflects the experience of households, and Panel B reflects supplier performance. ${ }^{34}$ From the household's perspective, we identified three phases in the connection process: Payment (A1), Wiring (which also includes submitting a metering application to Kenya Power) (A2), and Waiting (A3). Unexpected delays occurred during the wiring phase, which on average took 24 days, due to complications created by requirements for households to register for Kenya Revenue Authority certificates, spelling mistakes on wiring certificates, and communication breakdowns between REA and Kenya Power; see Appendix Note A3 for details. On average, households waited 188 days, after submitting all of their paperwork, before they began receiving electricity.

From the supplier's perspective, we identified four phases: Design (B1), Contracting (B2), Construction (B3), and Metering (B4). REA completed the design and contracting work, independent contractors (hired by REA) completed the physical construction, and Kenya Power educated households on issues relating to safety, and installed and activated the prepaid meters. The longest delays occurred during the design phase, which took an average of 57 days, and the metering phase, which took 68 days on average. The design phase was adversely affected by competing priorities at REA. ${ }^{35}$ There were severe delays during the metering phase due to unexpected issues at Kenya Power, such as insufficient materials (i.e., reported shortages in

\footnotetext{
${ }^{34}$ In Appendix Table A7, we document the full list of reasons for the delays encountered during each phase.

${ }^{35}$ In June 2014, the government announced a program to provide free laptops for all Primary Standard 1 students nationwide. Since roughly half of Kenya's primary schools were unelectrified at the time of the announcement, there was political pressure on REA to prioritize connecting the remaining unelectrified primary schools during the 201415 fiscal year. As a result, fewer REA designers were available to focus on other projects, including ours.
} 
prepaid meters), lost meter applications, and competing priorities for Kenya Power staff. Additional problems slowed the process as well. For several months, there was a general shortage of construction materials and metering hardware at REA storehouses. In the more remote communities, heavy rains created impassable roads. Difficulties in obtaining wayleaves (i.e., permission to pass electricity lines through other private properties) required redrawing network designs, additional trips to the storehouse, and further negotiations with contractors. In some cases, households that had initially declined a "ready board" changed their minds; in an unfortunate case lightning struck, damaging a household's electrical equipment; and so on. While these problems increased completion times, their negative effects were almost certainly offset (at least partially) by the weekly and persistent reminders sent to REA and Kenya Power by our project staff, meaning the situation for other rural Kenyans could be even worse. ${ }^{36}$

This experience highlights some common issues and the bureaucratic red tape that can delay the provision of electricity services in rural Kenya. The bottom line is that low observed demand for electricity connections may be due in part to households' expectations that they would encounter these sorts of lengthy delays.

Another major concern is the reliability of power. Electricity shortages and other forms of low grid reliability are well documented in less developed countries (Steinbuks and Foster 2010; Allcott, Collard-Wexler, and O'Connell 2016). In rural Kenya, households experience both short-term blackouts, which last for a few minutes up to several hours, and long-term blackouts, which can last for months and typically stem from technical problems with local transformers. During the 14-month period between September 2014 and October 2015 when households were being connected to the grid, we documented the frequency, duration, and primary reason for the long-term blackouts impacting our sample of communities. In total, 29 out of 150 transformers (19 percent) experienced at least one long-term blackout. On average, these blackouts lasted four months, with the longest blackout lasting an entire year. During these periods, households and businesses did not receive any grid electricity. The most common reasons included transformer burnouts, technical failures, theft, and replaced equipment. ${ }^{37}$ It seems obvious that the value a household places on a grid connection could be substantially lower when service is this unreliable. As a point of comparison, only 0.2 percent of transformers in California failed over

\footnotetext{
${ }^{36}$ At various points in the overall connection process, field enumerators reported that the electricity connection work may have been delayed due to expectations that bribes would be paid.

${ }^{37}$ In Appendix Table A8, we provide a full list of all of the communities that experienced long-term blackouts.
} 
the past five years, with the average blackout lasting a mere five hours. ${ }^{38}$ That said, there is no strong statistical evidence that a history of recent blackouts affects demand in the data: column 7 in Table 2 includes interactions between the treatment subsidy indicators and an indicator for whether any household in the community reported a recent blackout (i.e., over the past three days) at baseline, but finds no statistically significant effects.

Low demand may also be driven in part by household credit constraints, which are well documented in developing countries (De Mel, McKenzie, and Woodruff 2009; Karlan et al. 2014). In Figure 9, we compare the experimental results to two sets of stated willingness to pay results obtained in the baseline survey to shed some light on this issue. Stated willingness to pay might better capture household demand in the absence of credit constraints, although this is certainly debatable, since they might also overstate actual demand due to wishful thinking or social desirability bias (Hausman 2012).

Respondents were first asked whether they would accept a randomly assigned, hypothetical price-ranging from $\$ 0$ to $\$ 853$ - for a grid connection. ${ }^{39}$ Households were then asked whether they would accept the hypothetical offer if required to complete the payment in six weeks, a period chosen to be similar to the eight week payment period in the experiment. In Panel A, the first curve (long-dashed line, black squares) plots the results of the initial question. The second curve (long-dashed line, grey squares) plots the results of the follow-up question.

Stated demand is generally high. However, the demand curve falls dramatically when households are faced with a hypothetical time constraint, suggesting that households are unable to pay (or borrow) the required funds on relatively short notice, a strong indication that credit constraints are often binding, although an alternative interpretation is that the hypothetical question without time constraints generates exaggerated demand figures. ${ }^{40}$ At a price of $\$ 171$, for example, stated demand is initially 57.6 percent but it drops to 27.2 percent with the time constraint. Although the experimental demand curve is substantially lower than the stated demand without time limits, it closely tracks the constrained stated demand: at \$171, actual takeup in the experiment is 23.7 percent. The difference between the two contingent valuation results

\footnotetext{
${ }^{38}$ Based on personal communications with Pacific Gas and Electric Company (PG\&E) in December 2015.

${ }^{39}$ Each of $\$ 114, \$ 171, \$ 227, \$ 284$, and $\$ 398$ had a 16.7 percent chance of being drawn. Each of $\$ 0$ and $\$ 853$ had an 8.3 percent chance of being drawn. Nine households are excluded due to errors in administering the question.

${ }^{40}$ In Appendix Table A9A, we estimate the impact of the hypothetical offers on take-up. In Appendix Table A9B, we include interactions between the hypothetical offer indicators and key household covariates. In Appendix Figure A11, we plot hypothetical demand curves for households with and without bank accounts and high-quality walls.
} 
is consistent with the well-documented evidence on hypothetical bias (Murphy et al. 2005; Hausman 2012). However, the similarity between the constrained stated demand and experimental results suggest that augmenting standard stated preference survey questions to incorporate realistic timeframes and other contextual factors could help to elicit responses that more closely resemble revealed preference behavior.

We also regressed a binary variable indicating whether a household first accepted the hypothetical offer without the time constraint, but then declined the offer with the time constraint. Households with low-quality walls and respondents with no bank accounts are the most likely to switch their stated demand decision when faced with a pressing time constraint, consistent with the likely importance of credit constraints for these groups. ${ }^{41}$

In Section V.C above, we combined the experimental demand and cost curves and show that rural electrification may reduce social welfare. The stated preference results indicate that this outcome is likely to hold even if credit constraints were eased. For example, if we combine the cost curve with the stated demand for grid connections without time constraints, then all of the households in the unobserved $[0,16.7]$ domain of the stated demand curve (i.e., those willing to pay at least $\$ 853$ ) must be willing to pay on average $\$ 2,920$ in order for consumer surplus to be larger than total construction costs. While we cannot rule out that this is true, it appears unlikely in a rural setting where annual per capita income is below $\$ 1,000$ for most households.

One way to address credit constraints is to offer financing plans for grid connections. In a second set of baseline stated willingness to pay questions, each household was randomly assigned a hypothetical credit offer consisting of an upfront payment (ranging from $\$ 39.80$ to \$127.93), a monthly payment (ranging from \$11.84 to \$17.22), and a contract length (either 24 or 36 months); we provide details in Appendix Table A10. Households were first asked whether they would accept the offer (short-dashed line, black circles), and then whether they would accept the offer if required to complete the upfront payment in six weeks (short-dashed line, grey circles). In Figure 9, Panel B, we plot take-up against the net present value of the credit offers based on a reasonable though somewhat arbitrary annualized discount rate of 15 percent. $^{42}$

When households are offered financing, stated demand is not only high but also appears likely to be exaggerated, particularly when there are no time constraints to complete the upfront

\footnotetext{
${ }^{41}$ We report the results of this regression in Appendix Table A9C. As specified in our pre-analysis plan, we include a formal comparison of the stated willingness to pay and experimental curves in Appendix Table A9D.

${ }^{42} \mathrm{~A}$ range of discount rates and net present values is provided in Appendix Table A10, with largely similar results.
} 
payments. For example, 52.7 percent of households accepted the $\$ 915.48$ net present value offer, a package that consists of an upfront payment of $\$ 127.93$ and monthly payments of $\$ 26.94$ for 36 months (see Appendix Table A10). Eight weeks after accepting such an offer, a borrower will have paid \$181, with an additional \$915.92 due in the future. Yet stated demand for this option is twice as high as what we actually observe for the $\$ 171$ time-limited, all-in price offered to medium subsidy arm households in the experiment.

In Panel C, we combine the four stated demand curves with the experimental demand and average total cost curves. Visually, the only demand curves that appear to yield consumer surpluses that are potentially larger than total construction costs are the stated demand curves for grid connections with credit offers, which as we point out above, could be overstated. While not definitive, these patterns do not appear to overturn the basic observations above.

Finally, low demand may indicate that even with subsidies, grid connections are simply too expensive for many of the poor, rural households in our setting. After the experiment, we asked households that were connected in the low and medium subsidy arms to name any sacrifices they had made in order to complete their payments: 29 percent of households stated that they had forgone purchases of basic household consumption goods, and 19 percent stated that they had not paid school fees. It seems likely that many of the households that declined the subsidized offer did so due to binding budget constraints.

\section{Is rural electrification a socially desirable policy?}

The leading interpretation of our main empirical findings is that mass rural household electrification does not improve social welfare in Kenya, according to standard criteria. The cost of electrifying households appears to be at least four times higher than what households are willing and able to pay for these connections, and consumer surplus appears lower than total costs even with demand estimates that attempt to address credit constraints. While per household costs fall sharply with coverage levels, reflecting the large economies of scale in the creation of local grid infrastructure, they remain far higher than demand, implying that social welfare falls with each additional subsidized connection.

However, there may be additional benefits that are not captured by household willingness to pay. First, as outlined in Section II.B, there may be spillovers from private grid connections, including any benefits that unconnected households experience from being in close proximity to connected households. If these spillovers are positive and sufficiently large, take-up rates may be 
lower in communities with relatively high electrification rates at baseline, if households prefer to free ride on their neighbors' power. Yet in Section V.A above, we find no meaningful evidence of an interaction between the treatment indicators and either the overall baseline community electrification rate, or the proportion of neighboring households (within 200 meters) connected to electricity at baseline. This evidence is at best suggestive, however, since we cannot rule out the possibility that any negative effect of these spillovers on take-up is offset by a competing positive "keeping up with the neighbors" mechanism, as argued in Bernard and Torero (2015), or that greater learning about the private benefits of electricity and/or correlated household characteristics are present in addition to negative spillovers. Future research that directly measures the magnitude of household electrification spillovers, in terms of both usage and impacts on outcomes, would be useful in disentangling these factors.

Second, households may have limited information about the future income or broader welfare benefits of electrification, leading them to under-invest. Furthermore, there may be imperfect within-household altruism with respect to the benefits of electricity. Perhaps children stand to gain the most from indoor lighting in the evening, as it allows them to study and learn more, boosting their future earnings potential, but their parents do not fully understand these gains or incorporate them into their decision-making. Grid connections are long-lived, but their long-term benefits may not be fully reflected in willingness to pay if households are liquidity constrained, poorly informed, or face internal agency problems.

However, several other factors that we have not addressed may push up costs, making rural electrification less attractive. For example, access to modern energy could generate a number of negative environmental externalities. The impact on social welfare will therefore depend on the extent to which higher energy consumption results in greater $\mathrm{CO}_{2}$ emissions and other forms of pollution. Moreover, we have considered neither the costs nor economic impact of the initial investment to extend the high-voltage lines and install transformers in each community. Each transformer in our sample was set up to provide electricity to a critical public facility, such as a market, secondary school, or health clinic. Each installation required a large investment - the median cost of each deployed transformer is $\$ 21,820$ (Lee et al. 2016) - and the welfare gains from powering such facilities, while potentially quite large, have not been precisely measured. Our analysis treats these costs as sunk and focuses solely on the economics of electrifying "under grid" households, conditional on existing infrastructure. Given the 
growing support for large-scale policies to boost energy access, such as Kenya's planned LMCP, this is the policy-relevant question in our setting, but the broader costs of transformer installations would need to be considered in many other African and South Asian contexts.

\section{CONCLUSION}

Over the past century, rural electrification has served as a key benchmark for economic development and social progress. The United States began its mass rural electrification program in the late-1930s, though it required two decades to reach 90 percent of households (Kitchens and Fishback 2015), China did so in the 1950's, and South Africa launched its initiative in the 1990s, eventually reaching 49 percent. ${ }^{43}$ Today, access to affordable and reliable energy has emerged as a major political issue across many countries in Sub-Saharan Africa and South Asia, as they aim to repeat the successes of earlier mass electrification programs.

However, the extent to which increases in energy access should be driven by investments in large-scale infrastructure, such as grid connections, or small-scale decentralized solutions, such as solar lanterns and solar home systems, remains contested. Does Africa's energy future even lie with the grid? Although our findings suggest that household electrification may reduce social welfare, they do not necessarily imply that distributed solar systems are any more attractive than the grid, or that the patterns we identify are universal across time and space. In fact, the evidence - on inflated construction costs from leakage, and the pervasiveness of bureaucratic red tape, low grid reliability, and household credit constraints, all of which would suppress demand-suggests that the social welfare consequences of rural electrification are closely tied to organizational performance as well as economic and political institutions. Settings with better performance by the electricity utility — with fewer losses due to leakage and service that is more responsive to customers - may see shifts in both the cost curve and the demand side, and in such a setting mass rural electrification may indeed be the socially optimal policy. Another possibility is that mass electrification is indeed transformative and reshapes social, political, and economic interactions, perhaps in the long-run, but individual rural households do not internalize these benefits and they are thus not reflected in private demand estimates.

Decisions to invest in large-scale energy infrastructure programs are associated with major opportunity costs and long-run consequences for future economic development and

\footnotetext{
${ }^{43}$ In Appendix Table A11, we summarize historical rural electrification initiatives across several countries.
} 
climate change, especially in Sub-Saharan Africa, where access to electricity lags the rest of the world. Our findings indicate that connecting rural households is not necessarily an economically productive and high return activity in the world's poorest countries. The social returns to investments in transportation, education, health or other sectors-indeed possibly including the electrification of industrial sites or urban areas - need to be compared to investments in rural electricity grid expansion to determine appropriate public policy choices. Given the high stakes around these policy decisions, and the limited evidence base, there is a need for further research in a number of areas, including estimating the economic and broader social impacts of electric grid connections (as well as any community and regional spillovers), identifying the patterns and drivers of subsequent consumption demand, including for energy-efficient appliances, and determining routes to improved grid reliability and electric utility organizational performance.

\section{REFERENCES}

Abdullah, Sabah, P. Wilner Jeanty. 2011. "Willingness to Pay for Renewable Energy: Evidence from a Contingent Valuation Survey in Kenya." Renewable and Sustainable Energy Reviews 15(6): 2974-2983

Allcott, Hunt, Allan Collard-Wexler, Stephen D. O'Connell. 2016. "How Do Electricity Shortages Affect Industry? Evidence from India." American Economic Review 106(3): 587-624.

Aker, Jenny C. 2010. "Information from Markets Near and Far: Mobile Phones and Agricultural Markets in Niger." American Economic Journal: Applied Economics 2: 46-59.

Baumol, William J. 1977. "On the Proper Cost Tests for Natural Monopoly in a Multiproduct Industry." American Economic Review 67(5): 809-822.

Barron, Manuel, Maximo Torero. 2015. "Household Electrification and Indoor Air Pollution", unpublished manuscript.

Bernard, Tanguy, Maximo Torero. 2015. "Social Interaction Effects and Connection to Electricity: Experimental Evidence from Rural Ethiopia." Economic Development and Cultural Exchange 63(3): 459-484.

Bruhn, Miriam, David McKenzie. 2009. "In Pursuit of Balance: Randomization in Practice in Development Field Experiments." American Econ. Journal: Applied Economics 1(4): 200-232.

Burlig, Fiona and Louis Preonas. 2016. "Out of the Darkness and Into the Light? Development Effects of Electrification in India", unpublished manuscript.

Caine, Mark, et al. 2014. "Our High-Energy Planet: A Climate Pragmatism Project." The Breakthrough Institute. http://thebreakthrough.org/images/pdfs/Our-High-Energy-Planet.pdf.

Carlton, Dennis W., Jeffrey M. Perloff. 2005. Modern Industrial Organization. Boston: Pearson/Addison Wesley. 
Casey, Katherine, Rachel Glennerster, Edward Miguel. 2012. "Reshaping Institutions: Evidence on Aid Impacts Using a Preanalysis Plan." Quarterly Journal of Economics 127(4): 1755-1812.

Chakravorty, Ujjayant, Kyle Emerick, Majah-Leah Ravago. 2016. "Lighting Up the Last Mile: The Benefits and Costs of Extending Electricity to the Rural Poor", unpublished manuscript.

Christensen, Laurits R., and William H. Greene. 1976. "Economies of Scale in U.S. Electric Power Generation.” Journal of Political Economy 84(4): 655-676.

Craine, Stewart, Evan Mills, and Justin Guay. 2014. "Clean Energy Services for All: Financing Universal Electrification.” The Sierra Club.

de Mel, Suresh, David McKenzie, Christopher Woodruff. 2009. "Are Women More Credit Constrained? Experimental Evidence on Gender and Microenterprise Returns." American Economic Journal: Applied Economics 1(3): 1-32.

Devoto, Florencia, Esther Duflo, Pascaline Dupas, William Parente, Vincent Pons. 2012. "Happiness on Tap: Piped Water Adoption in Urban Morocco." American Economic Journal: Economic Policy 4(4): 68-99.

Deichmann, Uwe, Craig Meisner, Siobhan Murray, David Wheeler. 2010. "The Economics of Renewable Energy Expansion in Rural Sub-Saharan Africa.” Energy Policy 39(1): 215-227.

Dinkelman, Taryn. 2011. "The Effects of Rural Electrification on Employment: New Evidence from South Africa." American Economic Review 101(7): 3078-3108.

Donaldson, Dave. 2013. "Railroads of the Raj: Estimating the Impact of Transportation Infrastructure." American Economic Review.

Faber, Benjamin. 2014. "Trade Integration, Market Size, and Industrialization: Evidence from China's National Trunk Highway System." Review of Economic Studies, forthcoming.

Hausman, Jerry. 2012. "Contingent Valuation: From Dubious to Hopeless." Journal of Economic Perspectives 26(4): 43-56.

Kitchens, Carl, and Price Fishback. 2015. "Flip the Switch: The Impact of the Rural Electrification Administration 1935-1940." Journal of Economic History 75(4): 1161-1195.

IEA (International Energy Agency). 2014. Africa Energy Outlook.

Jensen, Robert. 2007. "The Digital Provide: Information (Technology), Market Performance, and Welfare in the South Indian Fisheries Sector." Quarterly Journal of Economics 122(3): 879-924.

Joskow, Paul. 2000. "Deregulation and Regulatory Reform in the U.S. Electric Power Sector," in Deregulation of Network Industries: What's Next? Sam Peltzman and Clifford Winston, eds. Washington, D.C.: AEI-Brookings Joint Center for Regulatory Studies, pp. 113-54.

Karlan, Dean, Robert Osei, Isaac Osei-Akoto, Christopher Udry. 2014. "Agricultural Decisions After Relaxing Credit and Risk Constraints." Quarterly Journal of Economics 129(2): 597-652. 
Lipscomb, Molly, Mobarak, Ahmed Mushfiq, Tania Barham. 2013. "Development Effects of Electrification: Evidence from the Topographic Placement of Hydropower Plants in Brazil." American Economic Journal: Applied Economics 5(2): 200-231.

Lee, Kenneth, Eric Brewer, Carson Christiano, Francis Meyo, Edward Miguel, Matthew Podolsky, Javier Rosa, Catherine Wolfram. 2016. "Electrification for "Under Grid" Households in Rural Kenya." Development Engineering 1: 26-35.

Lee, Kenneth, Edward Miguel, Catherine Wolfram. 2016. "Appliance Ownership \& Aspirations among Electric Grid and Home Solar Households in Rural Kenya.” NBER WP \#21949.

Mankiw, N. Gregory. 2011. Principles of Economics, 5th Edition. Cengage Learning.

Murphy, James J., P. Geoffrey Allen, Thomas H. Stevens, Darryl Weatherhead. 2005. "A MetaAnalysis of Hypothetical Bias in Stated Preference Valuation." Environmental and Resource Economics 30(3): 313-325.

Samuelson, Paul A., and William D. Nordhaus. 1998. Economics. Boston: Irwin/McGraw-Hill.

Parshall, Lily, Dana Pillai, Shashank Mohan, Aly Sanoh, Vijay Modi. 2009. "National Electricity Planning in Settings with Low Pre-Existing Grid Coverage: Development of a Spatial Model and Case Study of Kenya." Energy Policy 37(6): 2395-2410.

Patil, Sumeet R., et al. 2014. "The Effect of India's Total Sanitation Campaign on Defecation Behaviors and Child Health in Rural Madhya Pradesh: A Cluster Randomized Controlled Trial" PLoS Medicine 11(8): e1001709.

Reinikka, Ritva, Jakob Svensson. 2004. "Local Capture: Evidence from a Central Government Transfer Program in Uganda." Quarterly Journal of Economics 119(2): 679-705.

Steinbuks, J., and V. Foster. 2010. "When Do Firms Generate? Evidence on In-House Electricity Supply in Africa." Energy Economics 32(3): 505-14.

Viscusi, W. Kip, John M. Vernon, and Joseph Emmett Harrington. 2005. Economics of Regulation and Antitrust. Cambridge, Mass: MIT Press.

World Bank. 2008. "The Welfare Impact of Rural Electrification: A Reassessment of the Costs and Benefits. An IEG Impact Evaluation.” Washington, DC. DOI: 10.1596/978-0-8213-7367-5.

World Bank. 2016. "Doing Business 2016: Measuring Regulatory Quality and Efficiency." Washington, DC. DOI: 10.1596/978-1-4648-0667-4.

Yatchew, Adonis. 2000. "Scale Economies in Electricity Distribution: A Semiparametric Analysis." Journal of Applied Econometrics 15: 187-210.

Zvoleff, Alex, Ayse Selin Kocaman, Woonghee Tim Huh, and Vijay Modi. 2009. "The Impact of Geography on Energy Infrastructure Costs.” Energy Policy 37 (10): 4066-4078. 
Table 1-Differences between electricity grid unconnected vs. grid connected households at baseline

\begin{tabular}{lccc}
\hline \hline & Unconnected & Connected & $p$-value of diff. \\
& $(1)$ & $(2)$ & $(3)$ \\
\hline Panel A: Household head (respondent) characteristics & & \\
Female (\%) & 62.9 & 58.6 & 0.22 \\
Age (years) & 52.3 & 55.8 & $<0.01$ \\
Completed secondary schooling (\%) & 13.3 & 45.1 & $<0.01$ \\
Married (\%) & 66.0 & 76.7 & $<0.01$ \\
Not a farmer (\%) & 22.5 & 39.5 & $<0.01$ \\
Basic political awareness (\%) & 11.4 & 36.7 & $<0.01$ \\
Has bank account (\%) & 18.3 & 60.9 & $<0.01$ \\
Panel B: Household characteristics & & & \\
Number of members & 5.2 & 5.3 & 0.76 \\
Youth members (age $\leq 18)$ & 3.0 & 2.6 & 0.01 \\
High-quality walls (\%) & 16.0 & 80.0 & $<0.01$ \\
Land (acres) & 1.9 & 3.7 & $<0.01$ \\
Distance to transformer (m) & 356.5 & 350.9 & 0.58 \\
Monthly (non-charcoal) energy (USD) & 5.5 & 15.4 & $<0.01$ \\
Panel C: Household assets & & & $<0.01$ \\
Bednets & 2.3 & 3.4 & $<0.01$ \\
Sofa pieces & 6.0 & 12.5 & $<0.01$ \\
Chickens & 7.0 & 14.3 & $<0.01$ \\
Radios & 0.35 & 0.62 & $<0.01$ \\
Televisions & 0.15 & 0.81 & $<0.01$ \\
\hline Sample size & 2,289 & 215 & \\
\hline \hline
\end{tabular}

Notes: Columns 1 and 2 report sample means for households that were unconnected and connected at the time of the baseline survey. Column 3 reports $p$-value of the difference between the means. Basic political awareness indicator captures whether the household head was able to correctly identify the presidents of Tanzania, Uganda, and the United States. In the 2013 census of all unconnected households, just $5 \%$ of rural households were connected to the grid. In our sample of respondents, we oversampled the number of connected households. 
Table 2-Impact of grid connection subsidy on take-up of electricity connections

\begin{tabular}{|c|c|c|c|c|c|c|c|}
\hline & \multirow[b]{2}{*}{ (1) } & \multicolumn{6}{|c|}{ Interacted variable } \\
\hline & & $\begin{array}{l}\text { High- } \\
\text { quality } \\
\text { walls } \\
(2)\end{array}$ & $\begin{array}{l}\text { Attended } \\
\text { secondary } \\
\text { school } \\
\text { (3) }\end{array}$ & $\begin{array}{l}\text { Not a } \\
\text { farmer } \\
(4)\end{array}$ & $\begin{array}{l}\text { Baseline } \\
\text { electrifica- } \\
\text { tion } \\
\text { rate } \\
(5)\end{array}$ & $\begin{array}{c}\text { Baseline } \\
\text { neighbors } \\
\text { connected } \\
(6)\end{array}$ & $\begin{array}{c}\text { Report of } \\
\text { blackout } \\
\text { in past } 3 \\
\text { days } \\
\text { (7) }\end{array}$ \\
\hline T1: Low subsidy-29\% discount & $\begin{array}{c}5.94^{* * *} \\
(1.50)\end{array}$ & $\begin{array}{c}3.57^{* *} \\
(1.46)\end{array}$ & $\begin{array}{c}4.55^{* * *} \\
(1.38)\end{array}$ & $\begin{array}{c}5.36^{* * *} \\
(1.59)\end{array}$ & $\begin{array}{c}5.56^{* *} \\
(2.20)\end{array}$ & $\begin{array}{c}4.80^{* *} \\
(1.90)\end{array}$ & $\begin{array}{l}6.11^{* *} \\
(2.61)\end{array}$ \\
\hline T2: Medium subsidy $-57 \%$ discount & $\begin{array}{c}22.88^{* * *} \\
(4.02)\end{array}$ & $\begin{array}{c}21.30^{* * *} \\
(4.41)\end{array}$ & $\begin{array}{c}19.79^{* * *} \\
(3.80)\end{array}$ & $\begin{array}{c}20.10^{* * *} \\
(4.59)\end{array}$ & $\begin{array}{c}21.36^{* * *} \\
(6.18)\end{array}$ & $\begin{array}{c}21.38^{* * *} \\
(3.51)\end{array}$ & $\begin{array}{c}18.66^{* * *} \\
(5.11)\end{array}$ \\
\hline T3: High subsidy $-100 \%$ discount & $\begin{array}{c}94.97^{* * *} \\
(1.27)\end{array}$ & $\begin{array}{c}95.61^{* * *} \\
(1.17)\end{array}$ & $\begin{array}{c}95.18^{* * *} \\
(1.32)\end{array}$ & $\begin{array}{c}94.88^{* * *} \\
(1.38)\end{array}$ & $\begin{array}{c}97.51^{* * *} \\
(1.75)\end{array}$ & $\begin{array}{c}96.11^{* * *} \\
(1.31)\end{array}$ & $\begin{array}{c}95.11^{* * *} \\
(2.43)\end{array}$ \\
\hline Interacted variable & & $\begin{array}{c}0.26 \\
(1.35)\end{array}$ & $\begin{array}{l}-1.00 \\
(1.45)\end{array}$ & $\begin{array}{l}-0.75 \\
(0.91)\end{array}$ & $\begin{array}{c}0.14 \\
(0.11)\end{array}$ & $\begin{array}{c}0.05 \\
(0.05)\end{array}$ & $\begin{array}{l}-0.94 \\
(1.31)\end{array}$ \\
\hline $\mathrm{T} 1 \times$ interacted variable & & $\begin{array}{c}12.26^{* *} \\
(6.15)\end{array}$ & $\begin{array}{l}10.22 \\
(7.00)\end{array}$ & $\begin{array}{c}2.37 \\
(3.61)\end{array}$ & $\begin{array}{c}0.05 \\
(0.18)\end{array}$ & $\begin{array}{c}0.19 \\
(0.19)\end{array}$ & $\begin{array}{l}-0.18 \\
(3.13)\end{array}$ \\
\hline $\mathrm{T} 2 \times$ interacted variable & & $\begin{array}{c}8.85 \\
(7.77)\end{array}$ & $\begin{array}{c}19.54^{* * *} \\
(4.62)\end{array}$ & $\begin{array}{c}13.46^{*} \\
(7.71)\end{array}$ & $\begin{array}{c}0.29 \\
(1.21)\end{array}$ & $\begin{array}{c}0.31 \\
(0.23)\end{array}$ & $\begin{array}{c}7.58 \\
(7.80)\end{array}$ \\
\hline $\mathrm{T} 3 \times$ interacted variable & & $\begin{array}{l}-5.50 \\
(3.91)\end{array}$ & $\begin{array}{l}-4.28 \\
(4.92)\end{array}$ & $\begin{array}{c}0.31 \\
(2.40)\end{array}$ & $\begin{array}{c}-0.49^{*} \\
(0.30)\end{array}$ & $\begin{array}{l}-0.21 \\
(0.14)\end{array}$ & $\begin{array}{l}-0.22 \\
(2.78)\end{array}$ \\
\hline Take-up in control group & 1.30 & 1.30 & 1.30 & 1.30 & 1.30 & 1.30 & 1.30 \\
\hline Observations & 2176 & 2176 & 2176 & 2176 & 2176 & 2176 & 2176 \\
\hline R-squared & 0.69 & 0.69 & 0.70 & 0.69 & 0.69 & 0.69 & 0.69 \\
\hline
\end{tabular}

Notes: The dependent variable is an indicator variable (multiplied by 100) for household take-up. The mean of the dependent variable is 21.6. Robust standard errors clustered at the community level in parentheses. All specfications include the household and community covariates specified in the pre-analysis plan. Household covariates include the age of the household head, indicators for whether the household respondent attended secondary school, is a senior citizen, is not primarily a farmer, is employed, and has a bank account, an indicator for whether the household has high-quality walls, and the number of chickens (a measure of assets) owned by the household. Community covariates include indicators for the county, market status, whether the transformer was funded and installed early on (between 2008 and 2010), baseline electrification rate, and community population. Column 6 includes interactions with the proportion of neighbors (i.e., within 200 meters) connected to electricity at baseline. Column 7 includes interactions with an indicator for whether any household in the community reported a recent blackout (i.e., in the past three days) at baseline. Asterisks indicate coefficient statistical significance level (2-tailed): ${ }^{*} P<0.10 ;{ }^{* *} P<0.05 ;{ }^{* *} P<0.01$. The number of observations in the above regressions is somewhat smaller than the total number of households in our sample $(2,289)$ due to missing data. The coefficients do not change appreciably when the households with missing data are included in the regression with no covariates (as in column 1). 
Table 3-Impact of scale on average total cost (ATC) per household connection

\begin{tabular}{|c|c|c|c|c|c|c|c|}
\hline & \multicolumn{3}{|c|}{ Sample-OLS \& IV } & & & & \\
\hline & \multicolumn{2}{|c|}{ OLS } & \multirow{2}{*}{$\begin{array}{l}\text { IV } \\
(3) \\
\end{array}$} & \multicolumn{4}{|c|}{ Sample \& Designed_OLS } \\
\hline & (1) & (2) & & (4) & (5) & (6) & (7) \\
\hline Number of connections (M) & $\begin{array}{c}-472.43^{* * *} \\
(88.60)\end{array}$ & $\begin{array}{c}-510.07^{* * *} \\
(88.01)\end{array}$ & $\begin{array}{c}-492.53^{* *} \\
(198.98)\end{array}$ & $\begin{array}{c}-87.77^{* * *} \\
(15.11)\end{array}$ & & $\begin{array}{c}-81.11^{* * *} \\
(16.45)\end{array}$ & $\begin{array}{c}-96.68^{* * *} \\
(17.99)\end{array}$ \\
\hline $\mathrm{M}^{2}$ & $\begin{array}{c}20.40^{* * *} \\
(5.28)\end{array}$ & $\begin{array}{c}23.17^{* * *} \\
(5.27)\end{array}$ & $\begin{array}{l}22.05^{*} \\
(11.66)\end{array}$ & $\begin{array}{c}0.83^{* * *} \\
(0.18)\end{array}$ & & $\begin{array}{c}0.76^{* * *} \\
(0.20)\end{array}$ & $\begin{array}{c}1.05^{* * *} \\
(0.24)\end{array}$ \\
\hline Community coverage $(\mathrm{Q})$ & & & & & $\begin{array}{c}-84.34^{* * *} \\
(12.55)\end{array}$ & & \\
\hline$Q^{2}$ & & & & & $\begin{array}{c}0.75^{* * *} \\
(0.13)\end{array}$ & & \\
\hline Population & & & & & & & $\begin{array}{l}-0.46 \\
(0.97)\end{array}$ \\
\hline Population $\times$ M & & & & & & & $\begin{array}{c}0.02 \\
(0.08)\end{array}$ \\
\hline Population $\times \mathrm{M}^{2} / 100$ & & & & & & & $\begin{array}{l}-0.10 \\
(0.09)\end{array}$ \\
\hline Community controls & No & Yes & Yes & No & No & Yes & Yes \\
\hline Mean of dep. variable (USD) & 1813 & 1813 & 1813 & 1633 & 1633 & 1633 & 1633 \\
\hline S.D. of dep. variable & 1113 & 1113 & 1113 & 1065 & 1065 & 1065 & 1065 \\
\hline Observations & 62 & 62 & 62 & 77 & 77 & 77 & 77 \\
\hline $\mathrm{R}^{2}$ & 0.63 & 0.71 & - & 0.43 & 0.46 & 0.48 & 0.52 \\
\hline
\end{tabular}

Notes: The dependent variable is the budgeted average total cost (ATC) per connection in USD. Since there was no takeup in 13 communities, the sample size is reduced to 62 observations. In column 3, polynomials for the number of grouped connections, $M$ and $M^{2}$, are instrumented with $T^{M}$ and $T^{H}$, binary variables indicating whether the community was randomly assigned into the medium and high subsidy treatment arms, respectively. Columns 4 to 7 expand the sample to include the 15 additional designed communities. In these regressions, robust standard errors are clustered at the community level. Community coverage $(\mathrm{Q})$ is defined as the proportion of unconnected households that are ultimately connected (multiplied by 100). Community covariates (specified in the pre-analysis plan) include indicators for the county, market status, whether the transformer was funded and installed early on (between 2008 and 2010), baseline electrification rate, round-trip distance (to the REA warehouse in Kisumu), (demeaned) community population, and (demeaned) average land gradient. Asterisks indicate coefficient statistical significance level (2-tailed): ${ }^{*} P<0.10 ;{ }^{* *} P<0.05 ;{ }^{* * *} P<0.01$. 
Table 4-Costs of infrastructure construction associated with electricity connection projects

\begin{tabular}{|c|c|c|c|c|c|c|c|}
\hline & \multicolumn{2}{|c|}{ Budgeted } & \multicolumn{3}{|c|}{ Invoiced } & \multicolumn{2}{|c|}{ Difference } \\
\hline & Total & Per HH & Total & Per HH & Allocation & Amount & $\%$ \\
\hline \multicolumn{8}{|c|}{ Panel A: Project costs (reported) } \\
\hline Local network & 383,207 & 798 & 358,235 & 749 & $61.1 \%$ & $-24,972$ & $-6.5 \%$ \\
\hline Labor and transport & 177,457 & 370 & 200,080 & 419 & $34.1 \%$ & 22,623 & $12.7 \%$ \\
\hline Service lines & 15,812 & 33 & 27,684 & 58 & $4.7 \%$ & 11,873 & $75.1 \%$ \\
\hline Total cost & 576,476 & 1,201 & 585,999 & 1,226 & $100.0 \%$ & 9,523 & $1.7 \%$ \\
\hline \multicolumn{3}{|c|}{ Panel B: Project materials (reported and observed) } & \multicolumn{3}{|c|}{ Observed } & & \\
\hline Electricity poles & 1,449 & 3.0 & 1,141 & 2.4 & - & -308 & $-21.3 \%$ \\
\hline
\end{tabular}

Notes: In Panel A, project costs are reported in USD and consist of administrative budgeted estimates and final invoiced amounts. "Local network" consists of high- and low-voltage electricity poles and cables. "Labor and transport" also includes design work and small contingency items. "Service lines" are typically single "drop-down" cables that connect households to an electricity line. Kenya Power metering costs and houshold wiring costs are not included in this summary. In total, the project involved roughly $101.6 \mathrm{~km}$ of new low-voltage lines. In Panel B, we compare the budgeted number of electricity poles to the actual number of poles that were observed to have been installed. 
Figure 1-The electric utility as a natural monopoly

Panel A

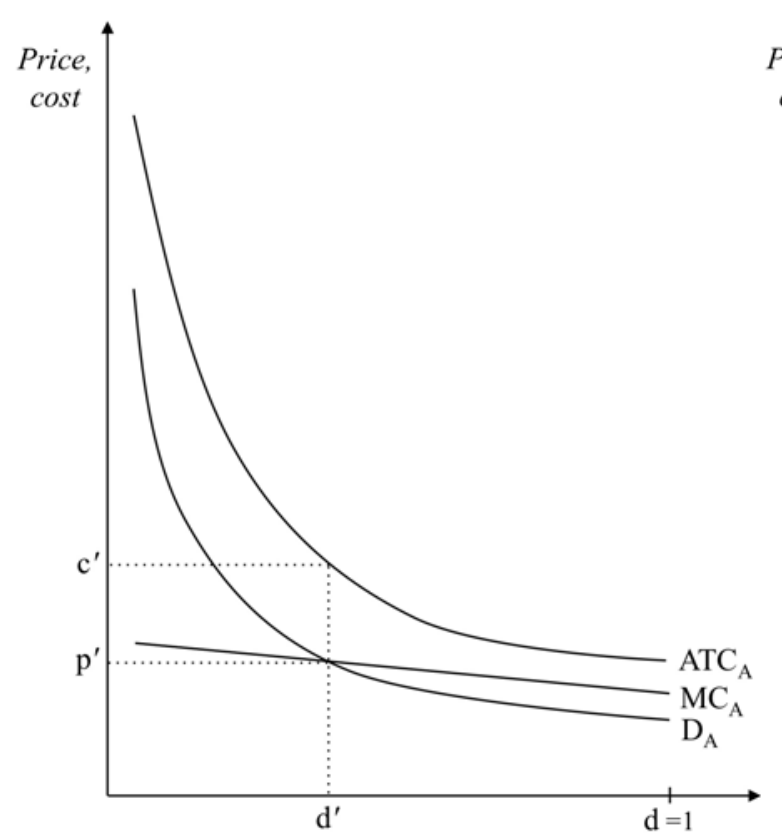

Take-up, community coverage
Panel B

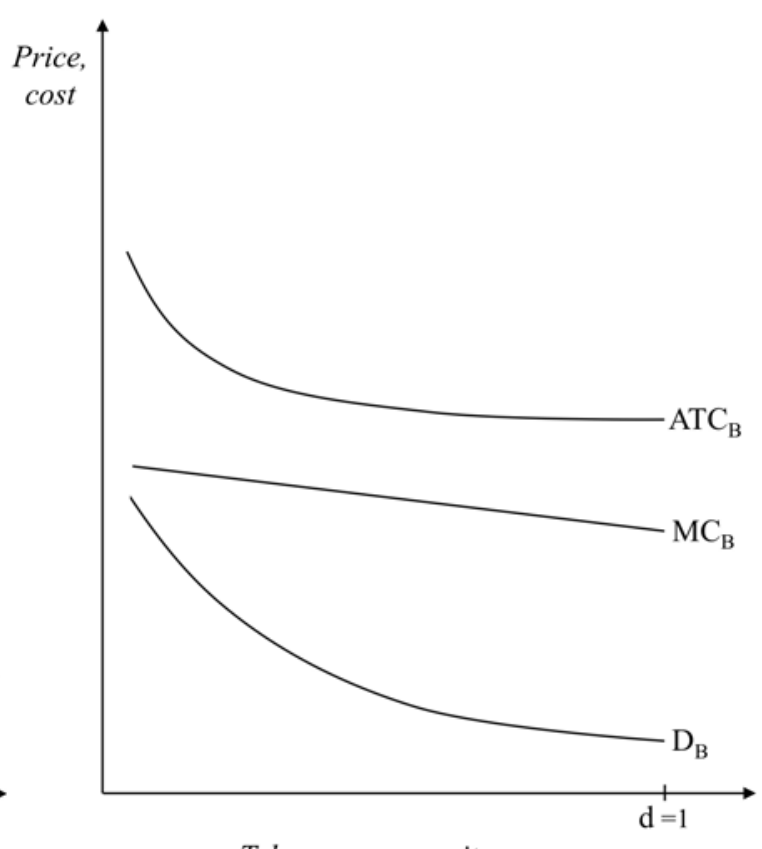

Take-up, community coverage
Panel C

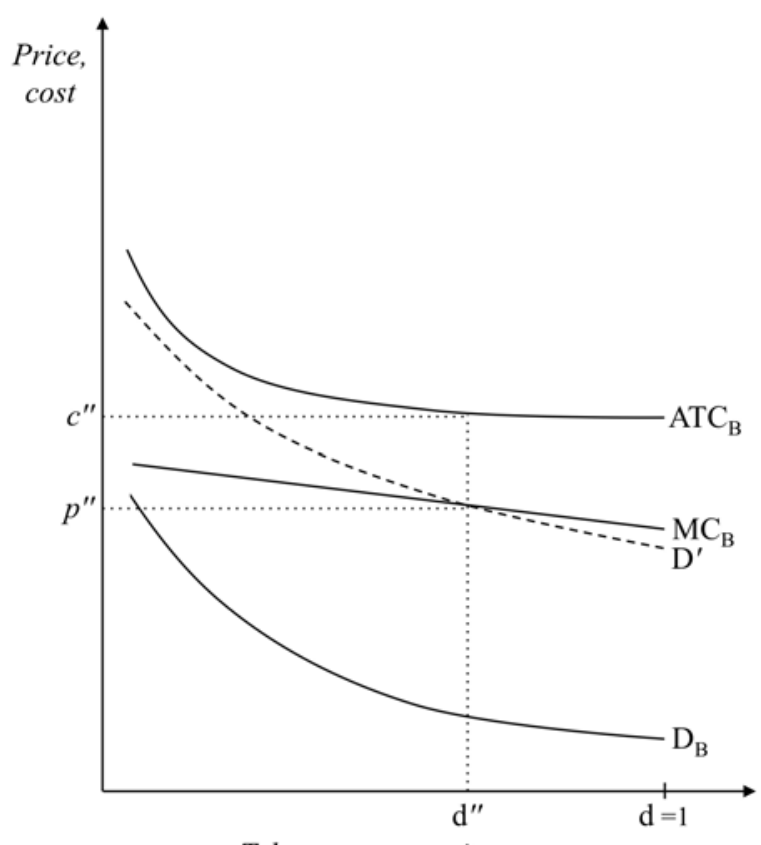

Take-up, community coverage

Notes: In Panel A, the electric utility is a natural monopoly facing high fixed costs, decreasing marginal costs $\left(\mathrm{MC}_{\mathrm{A}}\right)$, and decreasing average total costs $\left(\mathrm{ATC}_{\mathrm{A}}\right)$. In this case, $\mathrm{MC}_{\mathrm{A}}$ intersects demand at $\mathrm{d}^{\prime}$ and a government-subsidized mass electrification program can increase social welfare. Panel $B$ illustrates an alternative case in which $D_{B}$ does not intersect $M C_{B}$. In this case, a mass electrification program would not increase welfare unless there are, for example, positive externalities from private electricity connections. Panel C illustrates this scenario in which social demand $\left(\mathrm{D}^{\prime}\right)$ intersects $\mathrm{MC}_{\mathrm{B}}$ at $\mathrm{d}^{\prime \prime}$. 
Figure 2-Example of a "transformer community" of typical density

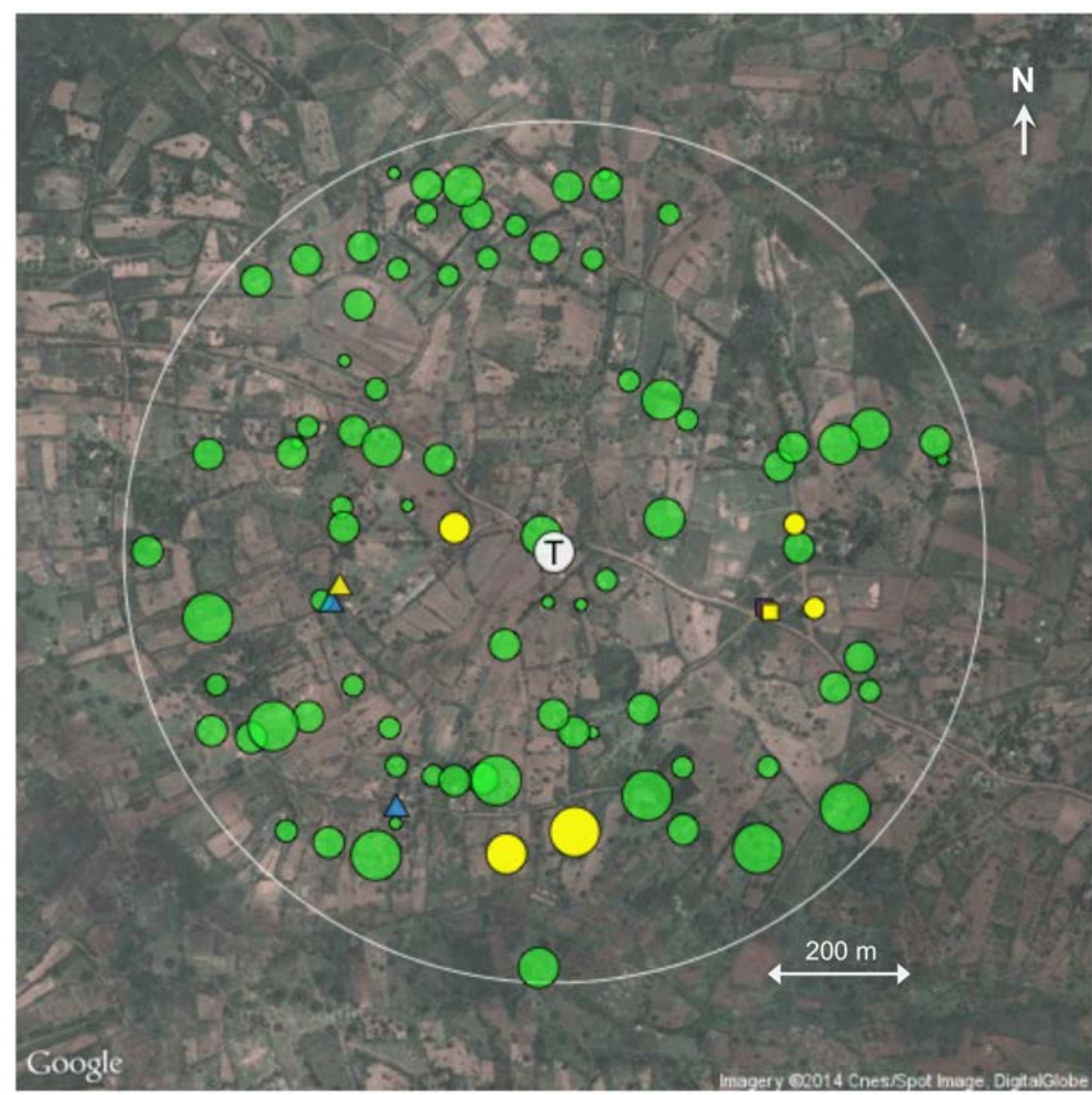

Notes: The white circle labeled $\mathrm{T}$ in the center identifies the location of the REA transformer. The larger white outline demarcates the 600-meter radius boundary. Green circles represent unconnected households; purple squares represent unconnected businesses; and blue triangles represent unconnected public facilities. Yellow circles, squares, and triangles indicate households, businesses, and public facilities with visible electricity connections, respectively. Household markers are scaled by household size, with the largest indicating households with more than ten members, and the smallest indicating single-member households. In each community, roughly 15 households were randomly sampled and enrolled into the study. The average density of a transformer community is 84.7 households per community and the average minimum distance between buildings (i.e., households, businesses, or public facilities) is 52.8 meters. In the illustrated community, there are 85 households. 
Figure 3-Experimental design

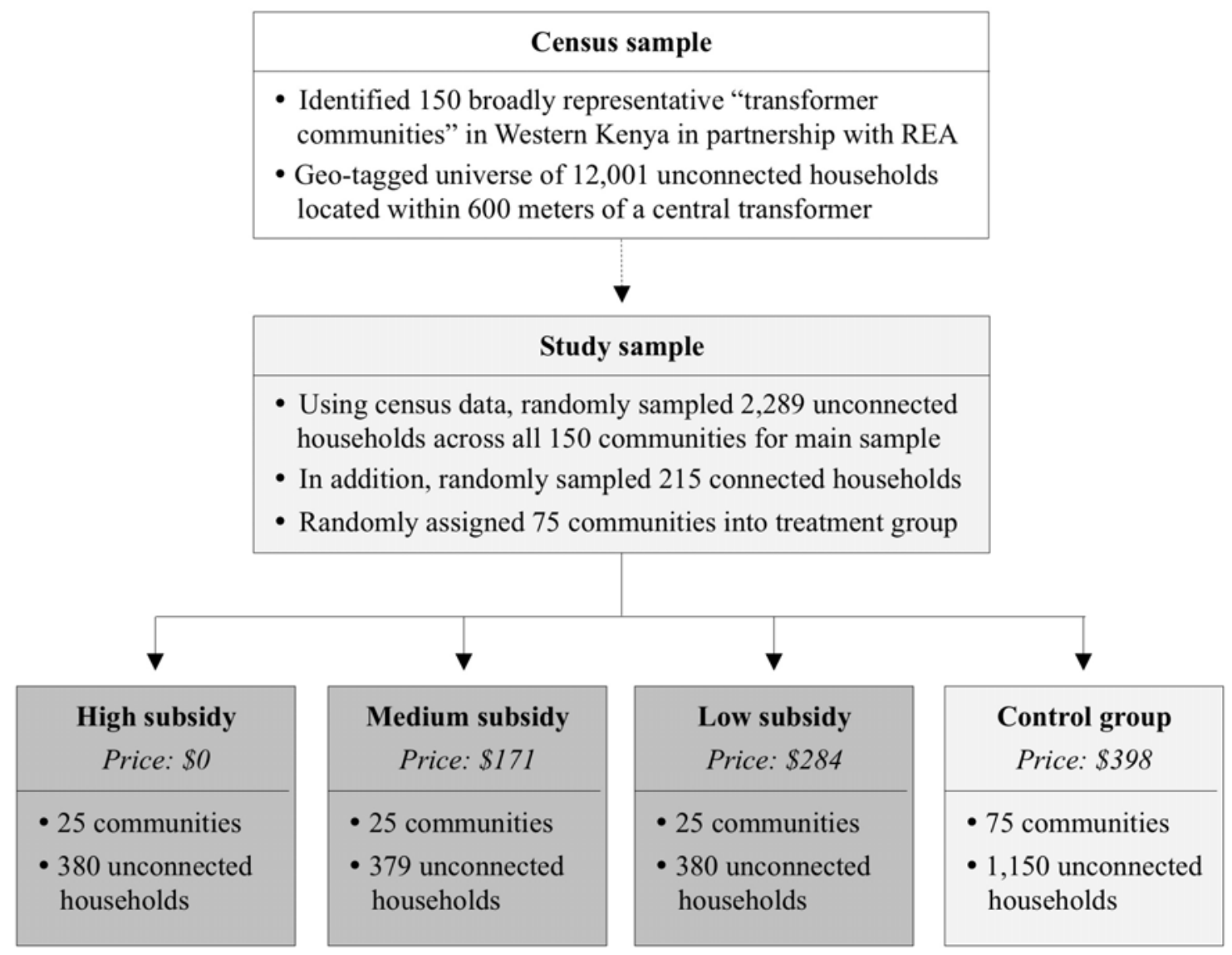

Notes: The 150 transformer communities in our sample covered $62.2 \%$ of the universe of REA projects in Busia and Siaya counties in August 2013. See Appendix for details on the community selection procedure. Each transformer community is defined as the group of all households located within 600 meters of a central electricity distribution transformer. All households within 600 meters of a transformer are eligible to apply for an electricity connection. In each of the 150 communities, roughly 15 unconnected households were randomly sampled (using a computer random number generator) and enrolled into our study. Census data on the universe of unconnected households were used as a sampling frame. Baseline surveys were also administered to a random sample of 215 households already connected at baseline. Communities were randomly assigned into three treatment arms and a control group. Treatment offers were distributed in two waves, between May and August 2014, and were valid for eight weeks. 
Figure 4-Experimental evidence on the demand for rural electrification

Panel A

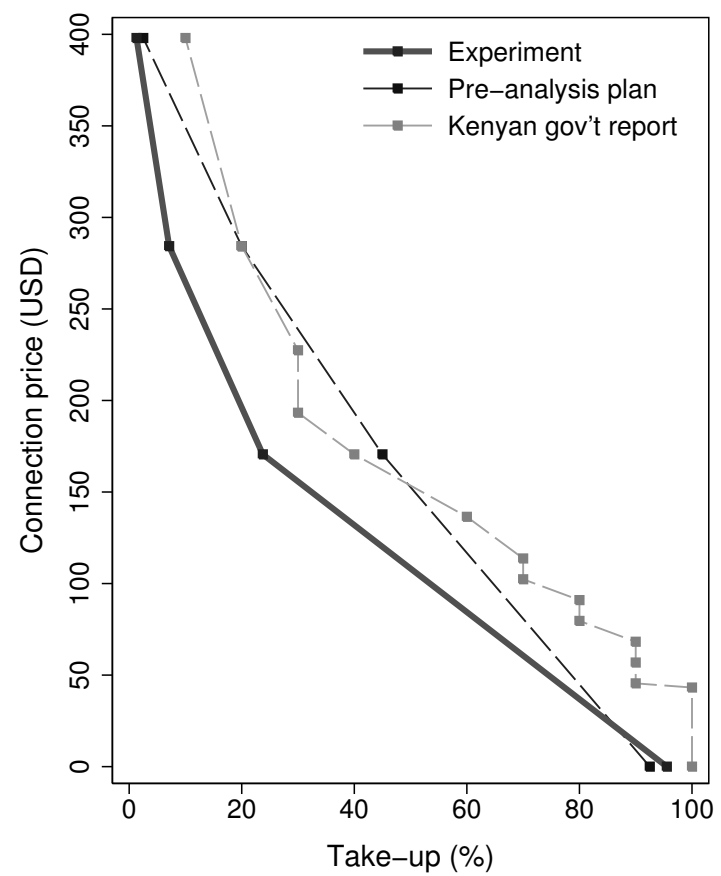

Panel B

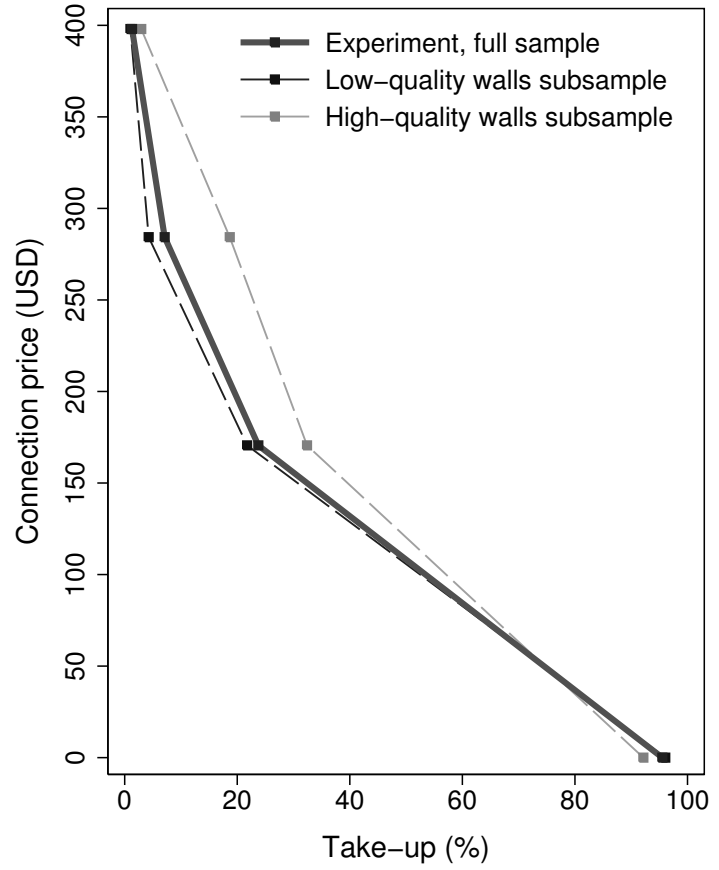

Notes: Panel A compares the experimental results with two sets of initial assumptions based on (i) our pre-analysis plan (see Appendix), and (ii) an internal government report shared with our team in early-2015. Panel B plots the results separately for households with low- and high-quality walls.

Figure 5-Experimental evidence on the costs of rural electrification

Panel A

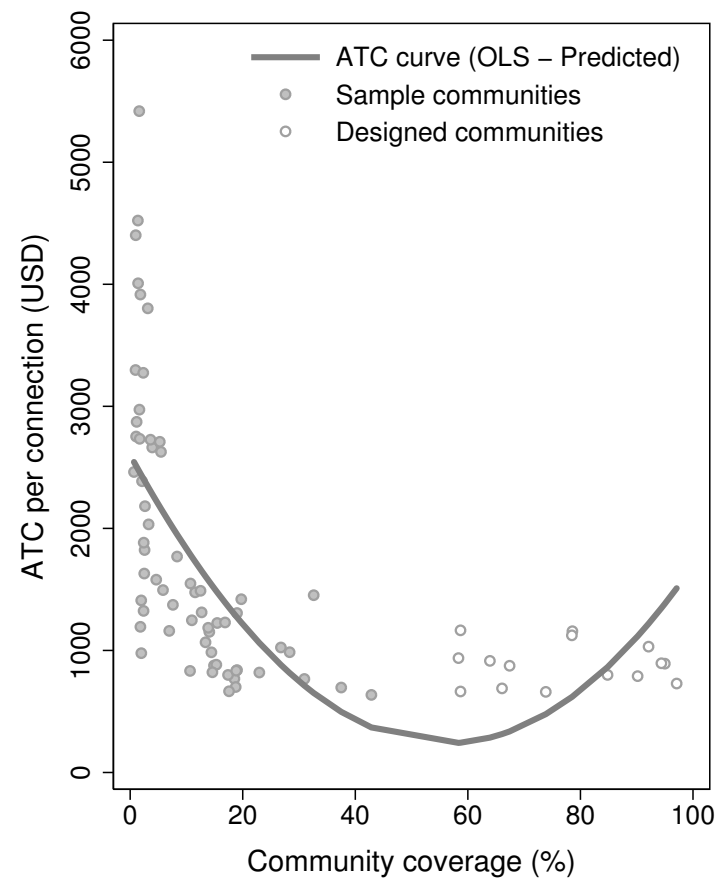

Panel B

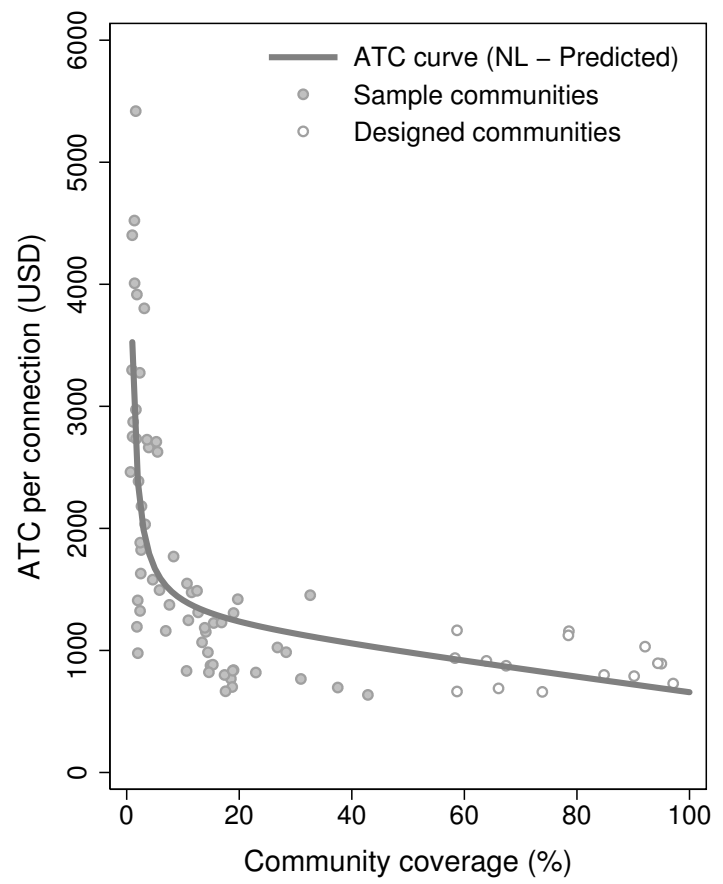

Notes: The above figures plot budgeted estimates of the average total cost (ATC) per connection at various levels of community coverage (i.e., electrification) for both sample and designed communities. Panel A displays the fitted curve from the regression reported in Table 3, column 5. Panel B displays predicted vaues from the nonlinear estimation of $A T C=b_{0} / Q+b_{1}+b_{2} Q$. 
Figure 6-Experimental estimates of the welfare implications of rural electrification

Panel A

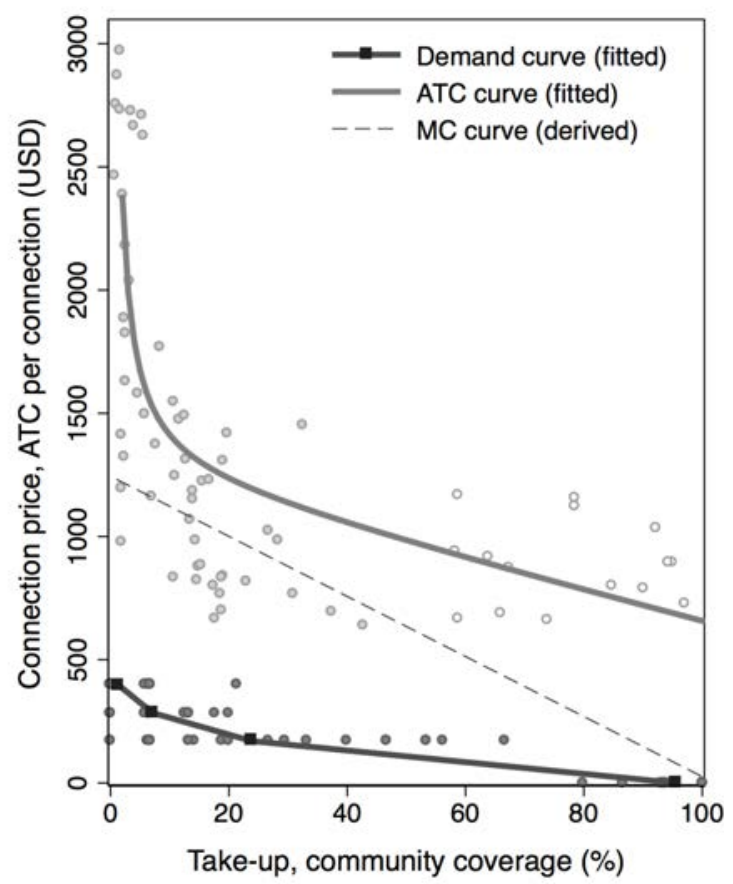

Panel B

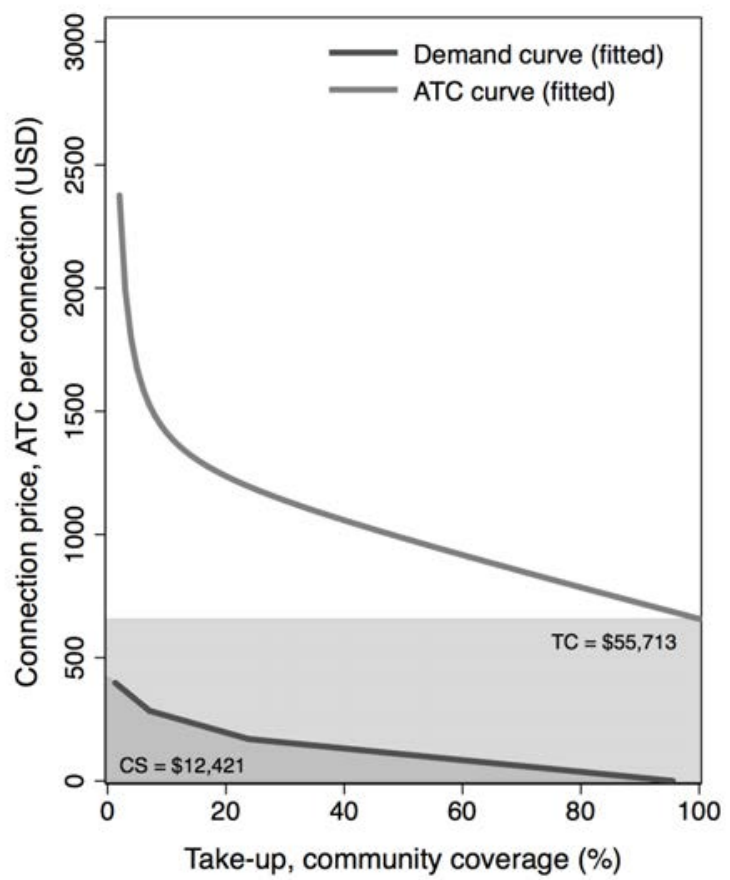

Panel C

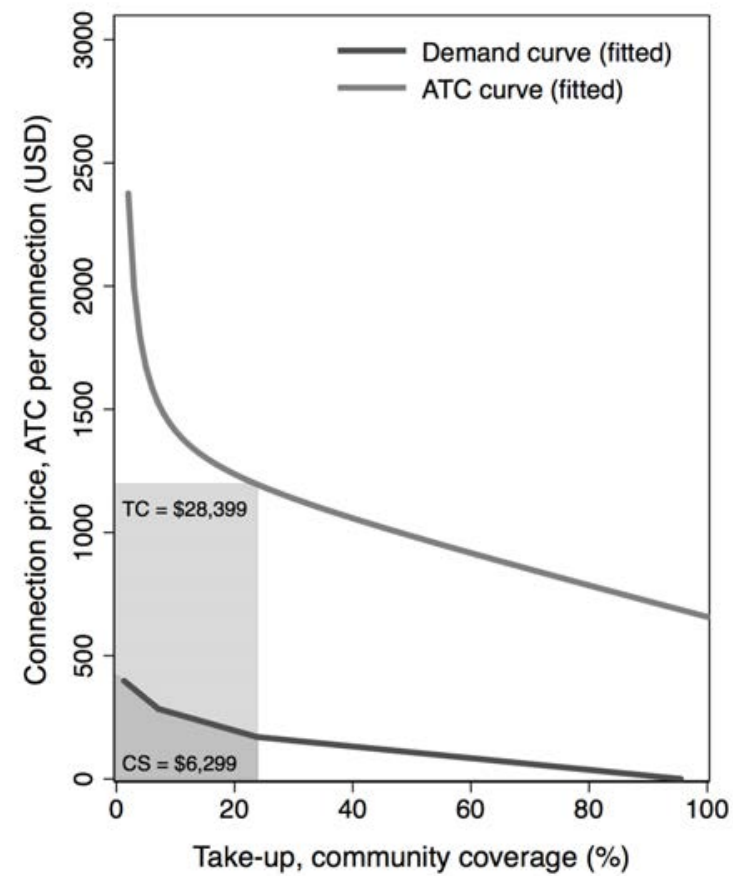

Notes: Panel A combines the experimental demand curve from Figure 4 with the experimental average total cost (ATC) curve from Figure 5, Panel $\mathrm{B}$. The marginal cost (MC) curve is generated by taking the derivative of the estimated total cost function. Panel B estimates the total cost of fully saturating a community at the cheapest ATC to be $\$ 55,713$, based on average community density of 84.7 households. Similarly, we estimate the area under the demand curve to be $\$ 12,421$. The area under the unobserved [0,1.3] domain is estimated by projecting the [1.3, 7.1] demand curve through the intercept. Results are robust to alternative assumptions regarding demand in the unobserved [0, 1.3] domain (see Appendix Figure A8). Calculations suggest that a mass electrification program would result in a welfare loss of $\$ 43,292$ per community. In order to justify such a program, discounted average future welfare gains of $\$ 511$ in social and economic impacts would be required per household. Panel $C$ presents the estimated demand for and costs of a program structured like the planned Last Mile Connectivity Project, which offers households a fixed price of $\$ 171$. In this case, only $23.7 \%$ of households would accept the price, and unless the government is willing to provide additional subsidies, the resulting electrification level would be low and there would be a welfare loss of $\$ 22,100$ per community. Discounted average future welfare gains of $\$ 1,099$ would be required per household. 
Figure 7-Discrepancies in project costs and electrical poles, by contractor

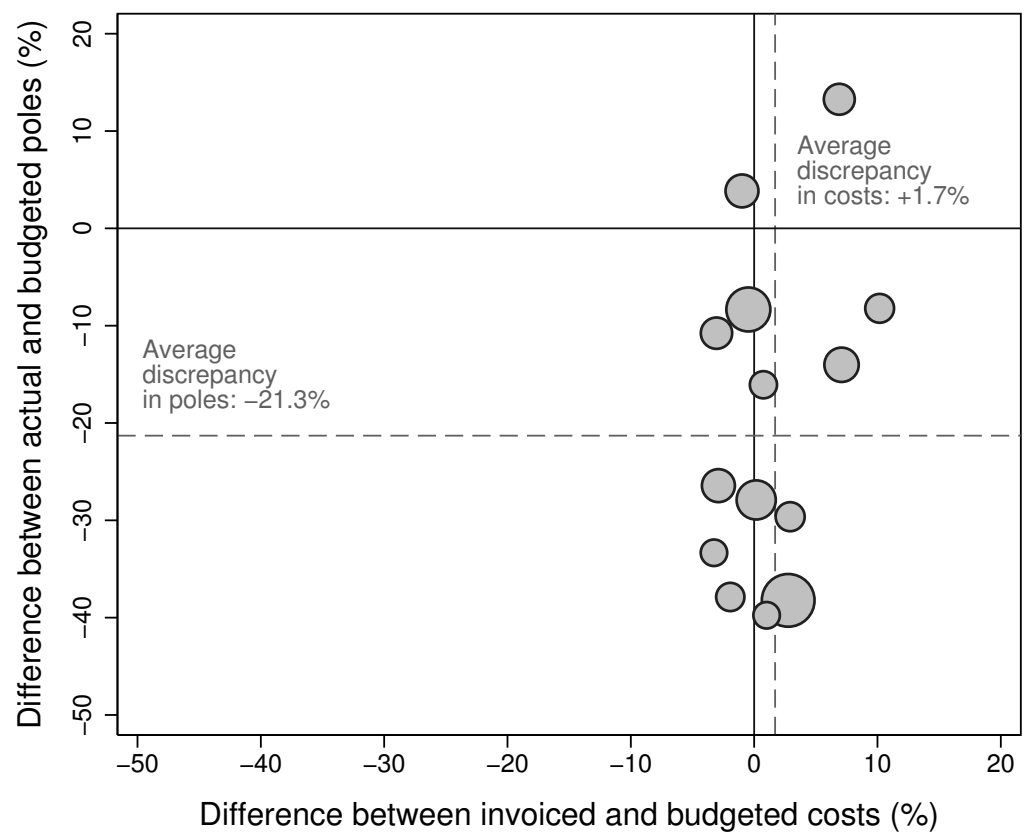

Notes: Each circle represents one of the 14 contractors that participated in the overall project. The size of each circle is proportional to the number of household connections supplied by the contractor (mean=34). The horizontal axis represents the percentage difference between the total invoiced and budgeted cost for each contractor. The vertical axis represents the percentage difference between the actual and designed poles (i.e. materials) for each contractor. The average discrepancies in poles and costs are weighted by the number of connections per contractor and correspond to the values in Table 4. 
Figure 8-Timeline of the rural electrification process

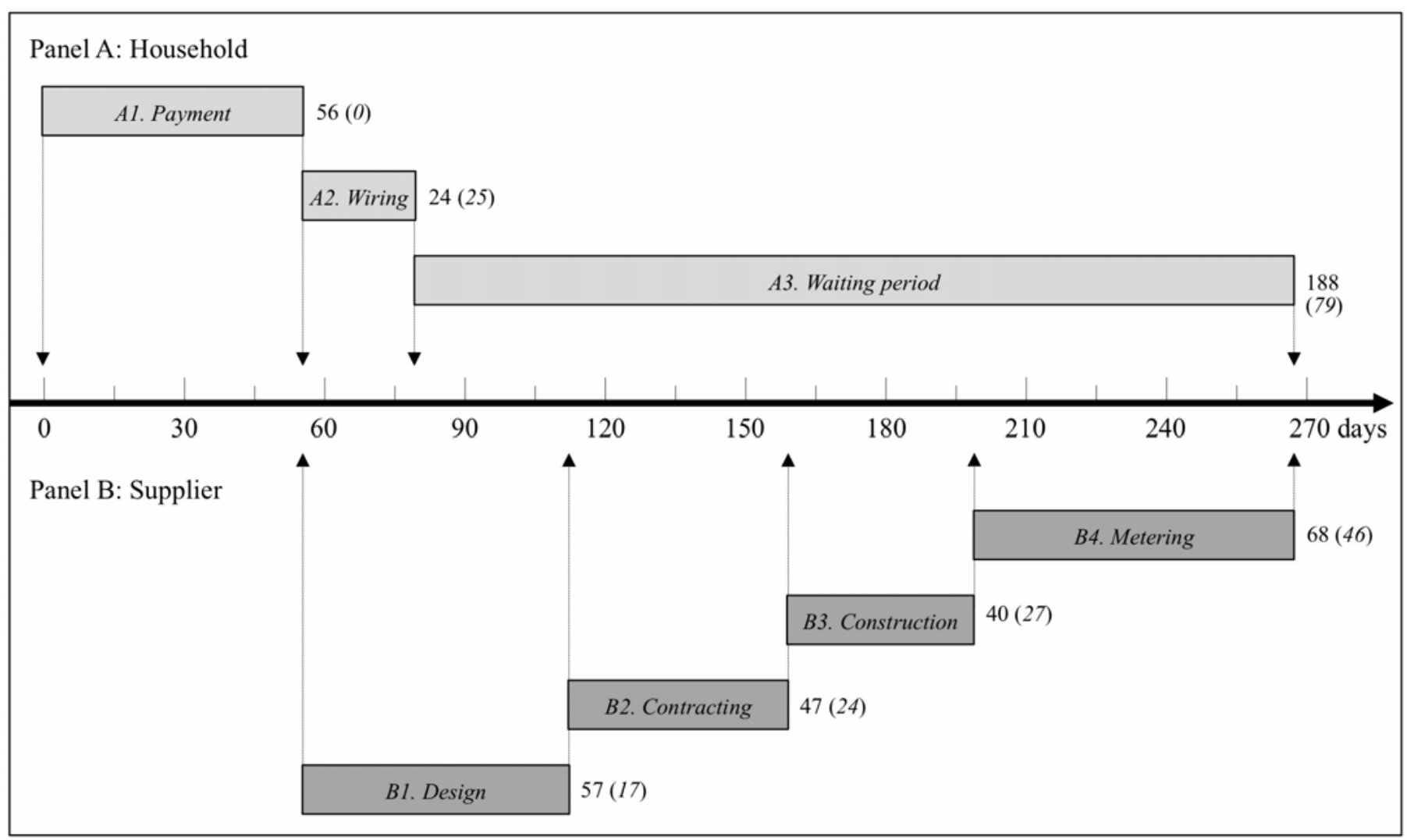

Notes: Panel A summarizes the rural electrification process from the standpoint of the household, divided into three key phases. Panel B summarizes the process from the standpoint of the supplier, divided into four key phases. The numbers to the right of each bar report the average number of days required to complete each phase (standard deviations in parantheses). Households were first given 56 days (8 weeks) to complete their payments. Afterwards, it took on average 212 days ( 7 months) for households to be metered and electricity to flow to the household. Appendix Table A7 lists specific issues that created delays during each phase of the process. 
Figure 9-Stated willingness to pay for an electricity connection, with and without time constraints and credit offers

Panel A

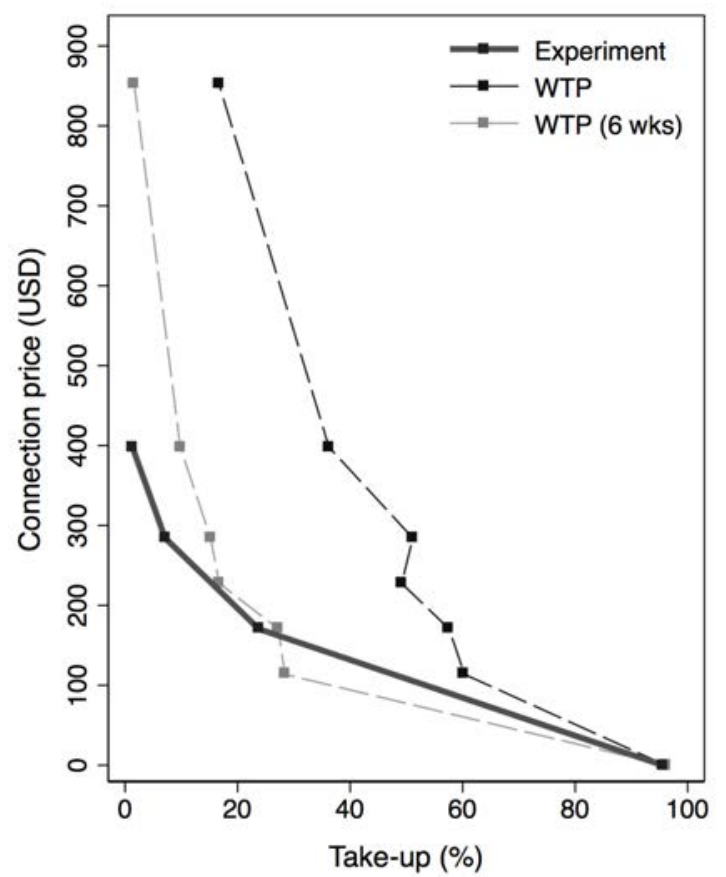

Panel B

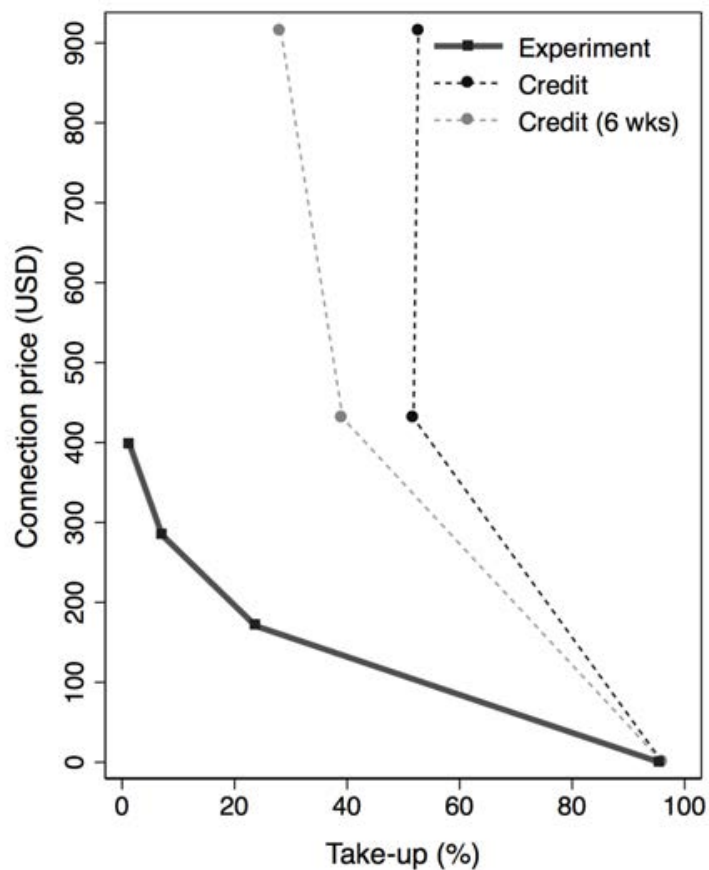

Panel C

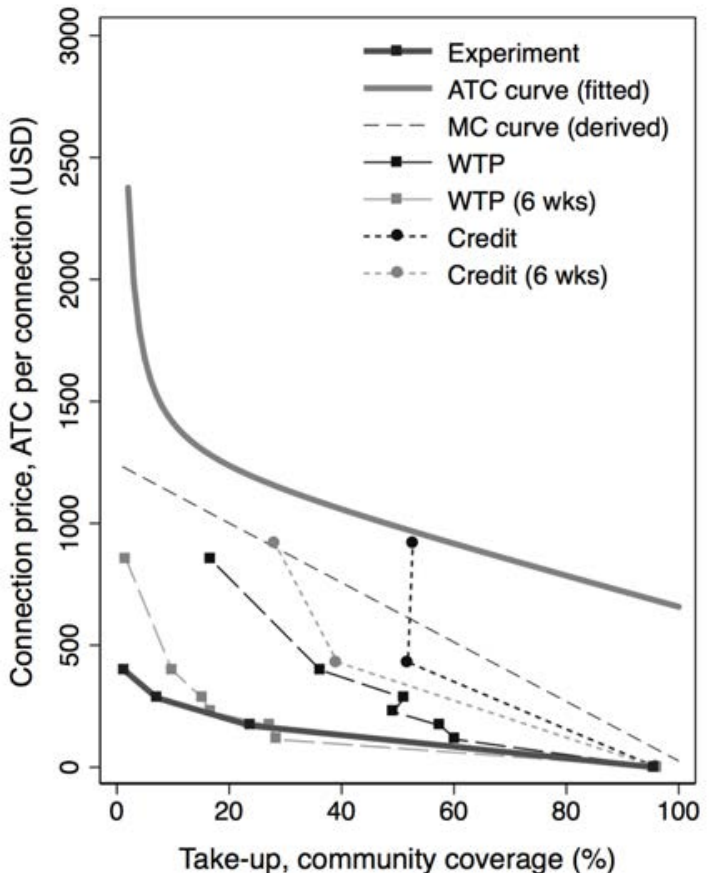

Notes: Panel A combines the experimental demand results (solid black line) with responses to a set of contingent valuation questions included in the baseline survey. Households were first asked whether they would accept a hypothetical offer (i.e., at a randomly assigned price) to connect to the grid (long-dashed line, black squares). Households were then asked whether they would accept the same hypothetical price offer if required to complete the payment in six weeks (long-dashed line, grey squares). Panel B combines the experimental demand results with responses to an alternative set of contingent valuation questions. Each household was randomly assigned a hypothetical credit offer consisting of an upfront payment (ranging from $\$ 39.80$ to $\$ 79.60$ ), a monthly payment (ranging from $\$ 11.84$ to $\$ 17.22$ ), and a contract length (either 24 or 36 months). Applying a discount rate of $15 \%$, we plot the net present value of the credit offers and the take-up results, with and without time constraints. Additional details on the credit offers are provided in Appendix Table A10. Panel C combines the stated and revealed demand curves with the experimental average total cost (ATC) curve from Figure 5, Panel B. 